\title{
Cost-effectiveness of medical primary prevention strategies to reduce absolute risk of cardiovascular disease in Tanzania: a Markov modelling study
}

Frida N. Ngalesoni ${ }^{1,4^{*}}$, George M. Ruhago ${ }^{2,4}$, Amani T. Mori ${ }^{2,3}$, Bjarne Robberstad ${ }^{3}$ and Ole F. Norheim ${ }^{4}$

\begin{abstract}
Background: Cardiovascular disease (CVD) is a growing cause of mortality and morbidity in Tanzania, but contextualized evidence on cost-effective medical strategies to prevent it is scarce. We aim to perform a cost-effectiveness analysis of medical interventions for primary prevention of CVD using the World Health Organization's (WHO) absolute risk approach for four risk levels.
\end{abstract}

Methods: The cost-effectiveness analysis was performed from a societal perspective using two Markov decision models: CVD risk without diabetes and CVD risk with diabetes. Primary provider and patient costs were estimated using the ingredients approach and step-down methodologies. Epidemiological data and efficacy inputs were derived from systematic reviews and meta-analyses. We used disability-adjusted life years (DALYs) averted as the outcome measure. Sensitivity analyses were conducted to evaluate the robustness of the model results.

Results: For CVD low-risk patients without diabetes, medical management is not cost-effective unless willingness to pay (WTP) is higher than US\$1327 per DALY averted. For moderate-risk patients, WTP must exceed US\$164 per DALY before a combination of angiotensin converting enzyme inhibitor (ACEI) and diuretic (Diu) becomes cost-effective, while for high-risk and very high-risk patients the thresholds are US\$349 (ACEl, calcium channel blocker (CCB) and Diu) and US\$498 per DALY (ACEI, CCB, Diu and Aspirin (ASA)) respectively. For patients with CVD risk with diabetes, a combination of sulfonylureas (Sulf), ACEI and CCB for low and moderate risk (incremental costeffectiveness ratio (ICER) US\$608 and US\$115 per DALY respectively), is the most cost-effective, while adding biguanide (Big) to this combination yielded the most favourable ICERs of US\$309 and US\$350 per DALY for high and very high risk respectively. For the latter, ASA is also part of the combination.

Conclusions: Medical preventive cardiology is very cost-effective for all risk levels except low CVD risk. Budget impact analyses and distributional concerns should be considered further to assess governments' ability and to whom these benefits will accrue.

Keywords: Sub-Saharan Africa, Tanzania, Primary prevention, Cardiovascular disease, Diabetes, Cost-effectiveness analysis, Markov modelling, Societal perspective

\footnotetext{
* Correspondence: frida.ngalesoni@igs.uib.no

${ }^{1}$ Ministry of Health and Social Welfare, Dar es Salaam, Tanzania

${ }^{4}$ Department of Global Public Health and Primary Health Care, University of

Bergen, Kalfarveien 31, Post box 7804NO-5020 Bergen, Norway

Full list of author information is available at the end of the article
} 


\section{Background}

Cardiovascular disease (CVD) is a growing cause of death and disability in sub-Saharan Africa (SSA). The Global Burden of Disease (GBD) 2010 study showed that, in 2000, ischemic heart disease and stroke accounted for 1.83 and $2.47 \%$ respectively of total disability- adjusted life years (DALYs) lost in the region. A decade later there had been a $15 \%$ increase in the percentage of total DALYs lost attributed to these conditions [1]. This surge has been boosted by ongoing nutritional, demographic and epidemiological transitions. Costs ascribed to CVD are substantial; for example, in 2010 , they amounted to about US $\$ 11.6$ billion in the World Health Organization's (WHO) African region E (AFRO E). These costs are expected to rise by $22 \%$ by 2030 [2]. Tanzania has not been spared from this tide, as evidence shows that the prevalence of CVD risk factors is increasing rapidly [3-8]. Consequently, large increases in avoidable CVD mortality and morbidity and hence serious pressures on the already constrained health systems are expected in the future unless preventive measures are implemented.

Many studies on the cost-effectiveness of preventive interventions into CVD have been conducted in highincome countries, with significant amounts of evidence in favour of primary prevention [9]. Evidence from individual countries in SSA is extremely scarce [10-12]. Only a few studies focusing on interventions across WHO and World Bank developing regions are available [13-15], and their use of aggregated data from countries with great diversity in terms of demographic, epidemiological, socio-economic and policy contexts requires the results to be interpreted with caution when used to inform policy in individual countries.

Preventive cardiology in Tanzania not only receives low priority but it is also practised in a non-comprehensive way [16-18]. Tanzania's previous and current preventive guidelines $[19,20]$ focus unilaterally on single risk factors but this approach has been shown to be less effective than the absolute risk approach advocated in the WHO's CVD preventive guidelines and elsewhere $[10,16,21,22]$. The absolute risk approach gives a numerical probability of a CVD event occurring in a given time period, e.g. one or ten years. It combines all modifiable major risk factors for CVD such as hypertension, cholesterol level and smoking. The absolute risk approach also includes unmodifiable factors like age and sex. Treatment decisions are then based on the total risk of a CVD event [23].

There is a previous study that has explored the costeffectiveness of medical preventive cardiology in Tanzania [12]. Being the first, it forms an important step for further exploration on the subject. A new study is justifiable for the following reasons: firstly, the previous study did not explicitly model diabetes in its risk factor profile. Existing literature indicates that diabetes is one of the major risk factors for CVD [24] and tends to occur together with other known cardiovascular risk factors [25]. Secondly, primary cost data were not used in the estimation of intervention costs. Thirdly, the current work expands from a provider to a societal perspective by including costs to patients of receiving treatment. Fourthly, following the release of GBD 2010 [26], new disability weights are available and the literature on drug effectiveness has since been updated. Finally, drugs such as simvastatin-which is listed on the national formulary and is currently available in Tanzania's Medical Stores Department (MSD)-have come off patent, and so are more likely to be affordable and therefore policy relevant for Tanzania. In light of the above reasons, the purpose of the present study is to perform a cost-effectiveness analysis of the most relevant medical interventions for primary prevention of CVD in Tanzania using an absolute risk approach.

\section{Methods \\ Model structure}

Two Markov decision models for CVD risk without diabetes and CVD risk with diabetes-reflecting whether or not there is diabetes in addition to all other CVD riskswere constructed using TreeAge Pro 2014 software for four CVD risk cohorts. Further model details are specified in Appendix 1 to permit full replication of our results.

\section{Absolute risk of CVD}

We constructed index cohorts representing each of the four CVD risk levels (see Appendix 1, Table 4) guided by the WHO's prediction charts for AFRO E. By varying age, gender, blood pressure, cholesterol level, smoking and diabetes status we obtained hypothetical cohorts representing low, medium, high and very high CVD risk levels, respectively [22].

\section{Description of interventions}

Table 1 below presents drug interventions included in the model.

These drugs are recommended by the WHO's CVD preventive guidelines [22], except for angiotensin receptor blocker $(\mathrm{ARB})$, which we included because its patent recently expired. For an overview of the drug combinations considered, see Appendix 2.

\section{Input parameters}

\section{Transition probabilities}

Annual risks for myocardial infarction (MI) and/or stroke were calculated from the Framingham Heart Study risk equations $[27,28]$ for the four different index cohorts. This was motivated by the absence of such data from the sub-Saharan region. Even though updated 
Table 1 Drug interventions for primary prevention of CVD

\begin{tabular}{llll}
\hline Drug class & Acronym & Drug & Daily dosage \\
\hline $\begin{array}{l}\text { Angiotensin converting } \\
\text { enzyme inhibitor }\end{array}$ & ACEl & Captopril & $12.5 \mathrm{mg}$ twice \\
$\begin{array}{l}\text { Angiotensin receptor } \\
\text { blocker }\end{array}$ & ARB & Losartan & $50 \mathrm{mg}$ once \\
Beta blocker & BB & Atenolol & $50 \mathrm{mg}$ once \\
Biguanide & Big & Metformin & $500 \mathrm{mg}$ thrice \\
Calcium channel blocker & CCB & Nifedipine & $20 \mathrm{mg}$ twice \\
Soluble aspirin & ASA & Aspirin & $75 \mathrm{mg}$ once \\
Statin & Sta & Simvastatin & $40 \mathrm{mg}$ once \\
Sulfonylureas & Sulf & Glibenclamide & $5 \mathrm{mg}$ once \\
Thiazide diuretics & Diu & Bendrofluazide & $2.5 \mathrm{mg}$ or $5 \mathrm{mg}$ \\
& & & once \\
\hline
\end{tabular}

Framingham equations are available from the literature, these could not be applied in this work since the reported annual risks are combined for all CVD events $[29,30]$. Age-specific background mortality rates were based on a Tanzanian life table [31] and were adjusted for the mortality attributable to CVD [32]. We used age and sex-specific case fatality rates from the WHO's $\mathrm{CHOosing}$ Interventions that are Cost-Effective (CHOICE) study [33] (Appendix 3, Table 5).

Since stroke was classified according to severity, information about the probabilities of "first ever stroke" and "subsequent stroke" was necessary. These were derived from context-specific literature and if data was unavailable we sought expert opinions or made assumptions (Appendix 3, Table 6). We assumed that the probability of subsequent strokes after the second event was constant.

\section{Intervention costs}

\section{Cost of CVD prevention and treatment}

The direct medical costs of providing medical primary prevention and cost to patients of receiving these services have been estimated elsewhere [34]. The provider cost of CVD treatment was identified and measured according to standard protocols from Arusha urban hospital using an ingredients approach. Resource valuation followed the opportunity cost method. Unit costs were estimated using activity-based and step-down methodologies. Patient cost of receiving CVD treatment was assumed to be $57.5 \%$ higher [35] than the US\$123 estimated as the patient cost of receiving CVD preventive measures [34]. The costing exercise follows a "narrow" societal perspective, whereby costs of health care, whether borne by the patient or the provider, are relevant. Since most economic evaluations are analyzed from the provider perspective only, a scenario analysis was conducted to explore the impact of this viewpoint on model recommendations. We assumed that primary preventive care can be performed within the existing facility setup and that upgrading of infrastructure is not required.

\section{Intervention effects}

The intervention effects-in terms of relative risk (RR)of drug classes used were retrieved from systematic reviews and meta-analyses of relevant randomized controlled trials, except for oral hypoglycemics which were based on one randomized controlled trial (RCT), see Appendix 3, Table 6 for references. Appendix 4 presents a summary of the comparators, RCT designs, statistical methods used and statements on primary prevention. The effects of interventions involving combinations of drugs were determined multiplicatively i.e. $\left(R_{1} \times R_{2} \times\right.$ $\mathrm{RR}_{\mathrm{n}}$ ) [36]. It was assumed that intervention effects did not vary across the different underlying risk groups and that it was constant across all age groups. We also assumed perfect adherence to treatment.

\section{Health outcome}

We used DALYs, which combine years lived with disability (YLDs) and years of life lost (YLLs), as our measure of health outcomes. YLDs were based on GBD 2010 disability weights of 0.422 for acute myocardial infarction and $0.021,0.076$ and 0.539 for mild, moderate and severe stroke respectively [26]. Tanzania's sex-specific life expectancy in 2012 and a disability weight of 1 to reflect the dead health state were used to calculate YLLs.

See Table 2 below for a summary of parameters and sources.

\section{Cost-effectiveness analysis}

For the CVD risk both without and with diabetes, expected costs and outcomes were calculated for each of the possible interventions. Base-case results are presented as incremental costs and effects and incremental cost-effectiveness ratios (ICERs). Strategies having ICERs below US\$610, which is Tanzania's 2012 GDP per capita [37], (the lowest willingness to pay (WTP) value recommended by the WHO [38]) were considered "very costeffective". In our base case, health costs and outcomes were non-differentially discounted at $3 \%$ annually. A scenario analysis was conducted to test whether and how results vary with differential discounting. Age weighting was not incorporated into the analysis due to criticisms raised in the GBD 2010 study [39].

\section{Sensitivity analyses}

The rationale behind performing a sensitivity analysis is that the uncertainty of the model parameters is mainly due to lack of data or ambiguity regarding how the data were collected, simplifications and assumptions made $[40,41]$. A set of one-way sensitivity analyses was 
Table 2 Model parameters and data sources

\begin{tabular}{ll}
\hline Parameter & Sources \\
\hline Annual risk of Ml or stroke - Table 5 & Framingham Heart Study \\
Non-MI or non-stroke mortality & Tanzanian 2012 life table and \\
rate - Table 5 & GHDx dataset \\
Fatality rate from Ml and stroke - Table 5 & WHO, CHOICE study \\
Cost of CVD prevention and & Authors' previous study and \\
treatment - Table 6 & primary analysis \\
Intervention costs and effects - Table 6 & Tanzania MSD and meta-analyses \\
Disability weights - Table 6 & Global burden of disease 2010 \\
Other transition probabilities - & Cross-sectional studies and \\
Table 6 & authors' extrapolation
\end{tabular}

MI Myocardial infarction, GHDx Global Health Data Exchange, WHO World Health Organization, CHOICE CHOosing Interventions that are Cost-Effective, MSD Medical Stores Department

performed to evaluate the impact of single assumptions about costs and outcomes on model results. Upper and lower variable ranges were taken from the reported $95 \%$ confidence interval or calculated from the standard error when stated. Otherwise we assumed a range of $+/-15 \%$ around the base case value. In the multivariate probabilistic uncertainty analysis, using a Monte Carlo simulation, we ran the model with distributions for each parameter rather than point estimates to determine the probability of optimal intervention being cost-effective against a range of cost-effectiveness thresholds [42, 43].

\section{Value of information analysis}

High-quality evidence from multiple model input sources is not always available and decisions based on these model recommendations are subject to costly uncertainty. A value of information analysis allows for an estimation of the cost of existing uncertainty, which is determined by the function of the probability that a decision will be wrong for different levels of WTP for health and the size of the opportunity loss if the wrong decision is made [44]. We first calculated expected value of perfect information (EVPI) as the difference between the expected net benefit with perfect information and current information, and then we estimated population EVPI assuming an annual effective hypothetical population of 1000 patients, discounted at a rate of $3 \%$ for 10 years.

\section{Results}

\section{Base-case results}

Table 3 below presents the base-case results for the two distinct models "CVD risk" and "CVD risk with diabetes" for the four CVD risk levels. In the table, all dominated and extendedly dominated strategies have been excluded. The complete tables presenting cost, incremental cost, effectiveness and incremental effectiveness of all strategies are available from the authors by request.

For both models, simpler treatment combinations appear most cost-effective for lower CVD risks, while higher risks led to more complex drug combinations being cost-effective. Generally, managing CVD risk is more cost-effective for patients with higher risk than for patients with lower risk, and more cost-effective for patients with diabetes than for patients without diabetes (Table 3).

\section{CVD risk}

\section{Low risk}

The results suggest that providing a combination of ACEI and Diu averts 0.41 DALYs at a cost of US\$544 compared to no treatment, yielding the lowest ICER of US\$1327 per DALY averted. Adding Sta to this duotherapy averted a further 0.08 DALYs for US\$254.

\section{Moderate risk}

As for the low risk, ACEI and Diu yielded the lowest ICER of US\$164 per DALY averted. Providing this intervention averts 1.02 DALYs at a cost of US\$167 compared to giving no medical treatment.

\section{High risk}

The lowest ICER of US\$349 per DALY averted was shown to result from providing a triple therapy of ACEI, $\mathrm{CCB}$ and Diu to high-risk patients compared to no treatment, whereby a cost of US\$545 deterred 1.56 DALYs. Adding Sta to this combination requires an addition of US\$607 per DALY averted.

\section{Very high risk}

Out of the three non-dominated strategies, a combination of ACEI, CCB, Diu and ASA yielded the lowest ICER value of US $\$ 498$ per DALY averted compared to "no treatment", by averting 2.44 DALYs for US $\$ 1216$. Adding Sta to this combination required an additional US\$189 to prevent a further 0.29 DALYs (Table 3).

\section{CVD risk with diabetes Low risk}

Model conclusions for this risk level suggest that a combination of Sulf, ACEI and CCB averts 0.85 DALYs at a lifetime cost of US\$517, resulting in an ICER of US\$608 per DALY averted. Adding Big to this combination will prevent a further 0.31 DALYs at an additional cost of US\$297, with an ICER of US\$958 per DALY averted. 
Table 3 Base case results for CVD risk without and with diabetes for four risk levels. All dominated strategies have been excluded

\begin{tabular}{|c|c|c|c|c|c|c|c|c|c|c|c|}
\hline \multicolumn{12}{|l|}{ CVD risk } \\
\hline Strategy & Cost & IC & Eff & IE & ICER & Strategy & Cost & IC & Eff & IE & ICER \\
\hline Low risk & & & & & & Moderate risk & & & & & \\
\hline No treatment & 461 & & 0.00 & & & No treatment & 1516 & & 0.00 & & \\
\hline ACEI_Diu & 1005 & 544 & 0.41 & 0.41 & 1327 & ACEI_Diu & 1683 & 167 & 1.02 & 1.02 & 164 \\
\hline ACEI_Diu_Sta & 1259 & 254 & 0.49 & 0.08 & 3175 & ACEI_Diu_Sta & 1827 & 144 & 1.28 & 0.26 & 554 \\
\hline High risk & & & & & & Very high risk & & & & & \\
\hline No treatment & 1695 & & 0.00 & & & No treatment & 2028 & & 0.00 & & \\
\hline ACEl_CCB_Diu & 2240 & 545 & 1.56 & 1.56 & 349 & ACEI_CCB_Diu_ASA & 3244 & 1216 & 2.44 & 2.44 & 498 \\
\hline ACEI_CCB_Diu_Sta & 2404 & 164 & 1.83 & 0.27 & 607 & ACEI_CCB_Diu_Sta_ASA & 3433 & 189 & 2.73 & 0.29 & 652 \\
\hline \multicolumn{12}{|l|}{ CVD risk with diabetes } \\
\hline Strategy & Cost & IC & Eff & IE & ICER & Strategy & Cost & IC & Eff & IE & ICER \\
\hline Low risk & & & & & & Moderate risk & & & & & \\
\hline No treatment & 964 & & 0.00 & & & No treatment & 1805 & & 0.00 & & \\
\hline Sulf_ACEl_CCB & 1481 & 517 & 0.85 & 0.85 & 608 & Sulf_ACEI_CCB & 1966 & 161 & 1.40 & 1.40 & 115 \\
\hline Big_Sulf_ACEI_CCB & 1778 & 297 & 1.16 & 0.31 & 958 & Big_Sulf_ACEI_CCB & 2122 & 156 & 2.01 & 0.61 & 256 \\
\hline Big_Sulf_ACEI_CCB_Sta & 2026 & 248 & 1.26 & 0.10 & 2480 & Big_Sulf_ACEI_CCB_Sta & 2311 & 189 & 2.21 & 0.20 & 945 \\
\hline High risk & & & & & & Very high risk & & & & & \\
\hline No treatment & 1909 & & 0.00 & & & No treatment & 2514 & & 0.00 & & \\
\hline Big_Sulf_ACEI_CCB & 2576 & 667 & 2.16 & 2.16 & 309 & Big_Sulf_ACEI_CCB_ASA & 3696 & 1182 & 3.38 & 3.38 & 350 \\
\hline Big_Sulf_ACEI_CCB_Sta & 2768 & 192 & 2.37 & 0.21 & 914 & Big_Sulf_ACEI_CCB_Sta_ASA & 3893 & 197 & 3.66 & 0.28 & 704 \\
\hline Big_Sulf_ACEI_ARB_CCB_Sta & 3798 & 1030 & 2.47 & 0.10 & 10300 & Big_Sulf_ACEI_ARB_CCB_Sta_ASA & 4883 & 990 & 3.79 & 0.13 & 7615 \\
\hline
\end{tabular}

IC Incremental cost, Eff Effectiveness, IE Incremental effectiveness, ICER Incremental cost-effectiveness ratio

\section{Moderate risk}

As for the low risk with diabetes, the triple therapy of one oral hypoglycemic and two anti-hypertensives yielded the lowest ICER of US\$115 per DALY averted compared to not providing medical management. A more complex strategy of adding a second oral hypoglycemic required an additional US\$156 to deter a further 0.61 DALYs with an ICER of US\$256 per DALY averted.

\section{High risk}

Just over 2 DALYs are averted at a cost of US $\$ 667$ by giving two oral hypoglycemics (Big \& Sulf) and two antihypertensives (ACEI \& CCB), with an ICER of US\$309 per DALY averted. Additional DALYs are avoided at further cost and with more complex combinations. Adding Sta to this combination will further prevent 0.21 DALYs at a cost of US\$192 while further addition of ARB deterred only 0.10 DALYs at a cost of US\$1030. Corresponding ICERs are US\$914 and US\$10,300 per DALY averted respectively compared to the preceding interventions.

\section{Very high risk}

The lowest ICER was achieved by providing Big, Sulf, ACEI, CCB and ASA, whereby a cost of US $\$ 1182$ deterred 3.38 DALYs with an ICER of US\$350 per DALY averted.

\section{Representing uncertainty}

In this sub-section, only the results for low and very high CVD risk without and with diabetes are presented, due to space limitations. For the results for moderate and high risks see Appendix 5.

\section{Deterministic sensitivity analysis}

Drug treatment effects are shown to be the most uncertain parameters for both low and very high CVD risk without and with diabetes. Variables representing less than $1 \%$ of the total uncertainty were omitted since changing their assumptions had a negligible effect on the model. (Figs. 1 and 2).

\section{Probabilistic sensitivity analysis}

Figures 3 and 4 illustrate the optimal treatment paths, or cost-effectiveness acceptability frontiers (CEAFs), for low and very high CVD risk without and with diabetes for varying levels of plausible WTP to avert a DALY. For each level of WTP, the CEAFs illustrate only the optimal 


\section{a}

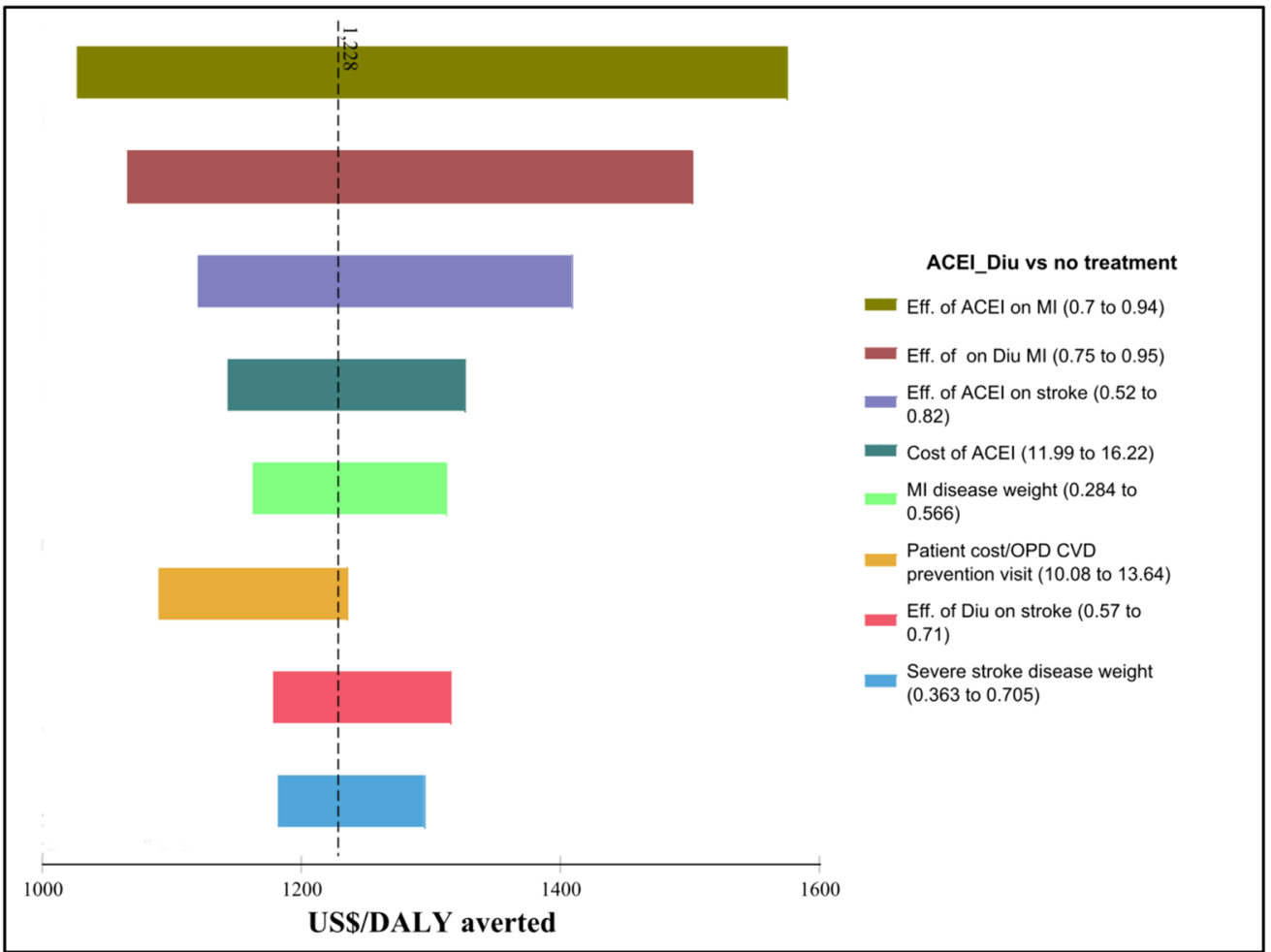

b

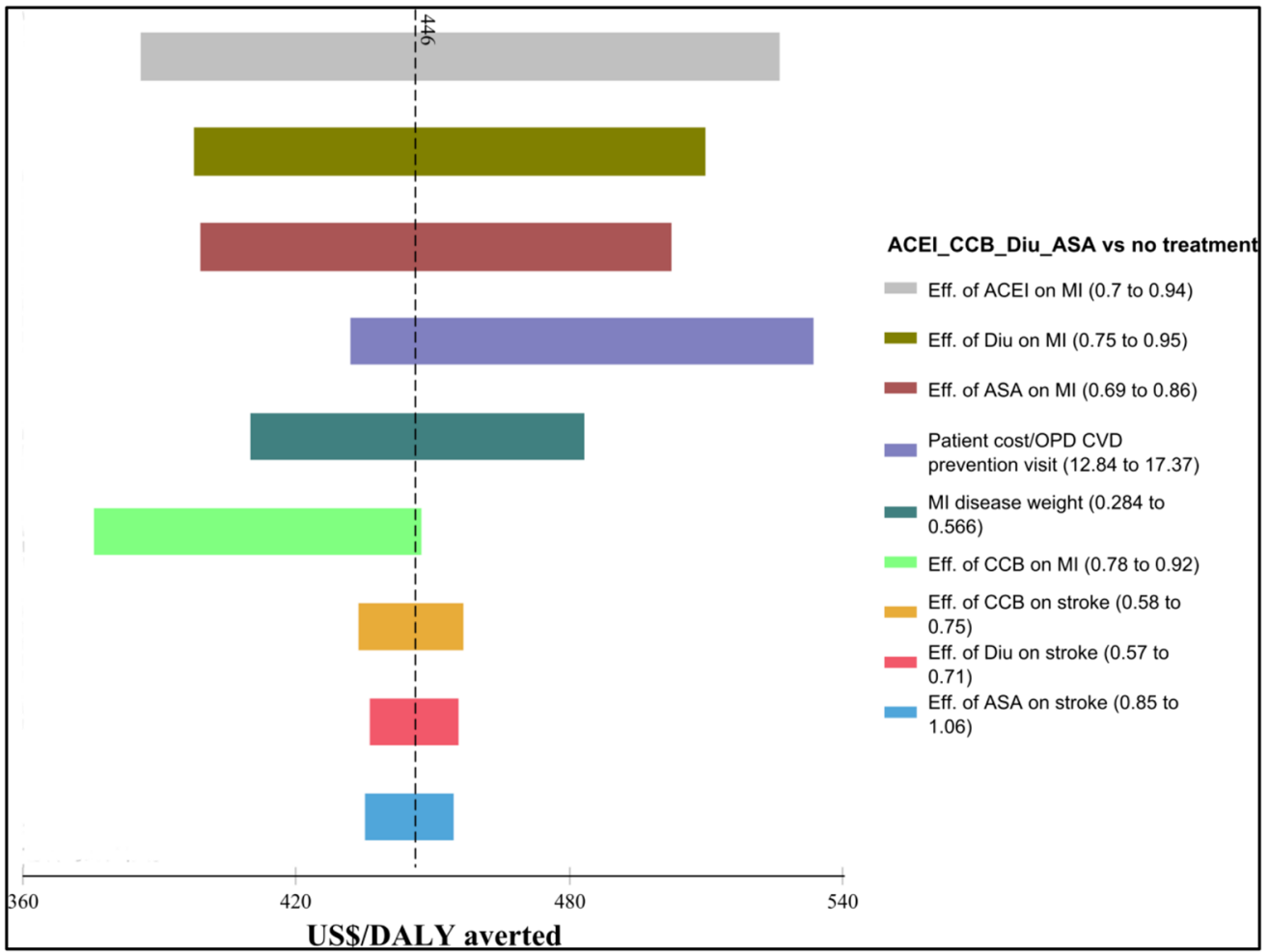

Fig. 1 ICER tornado diagrams for low and very high CVD risk. a Low CVD risk. b Very high CVD risk 


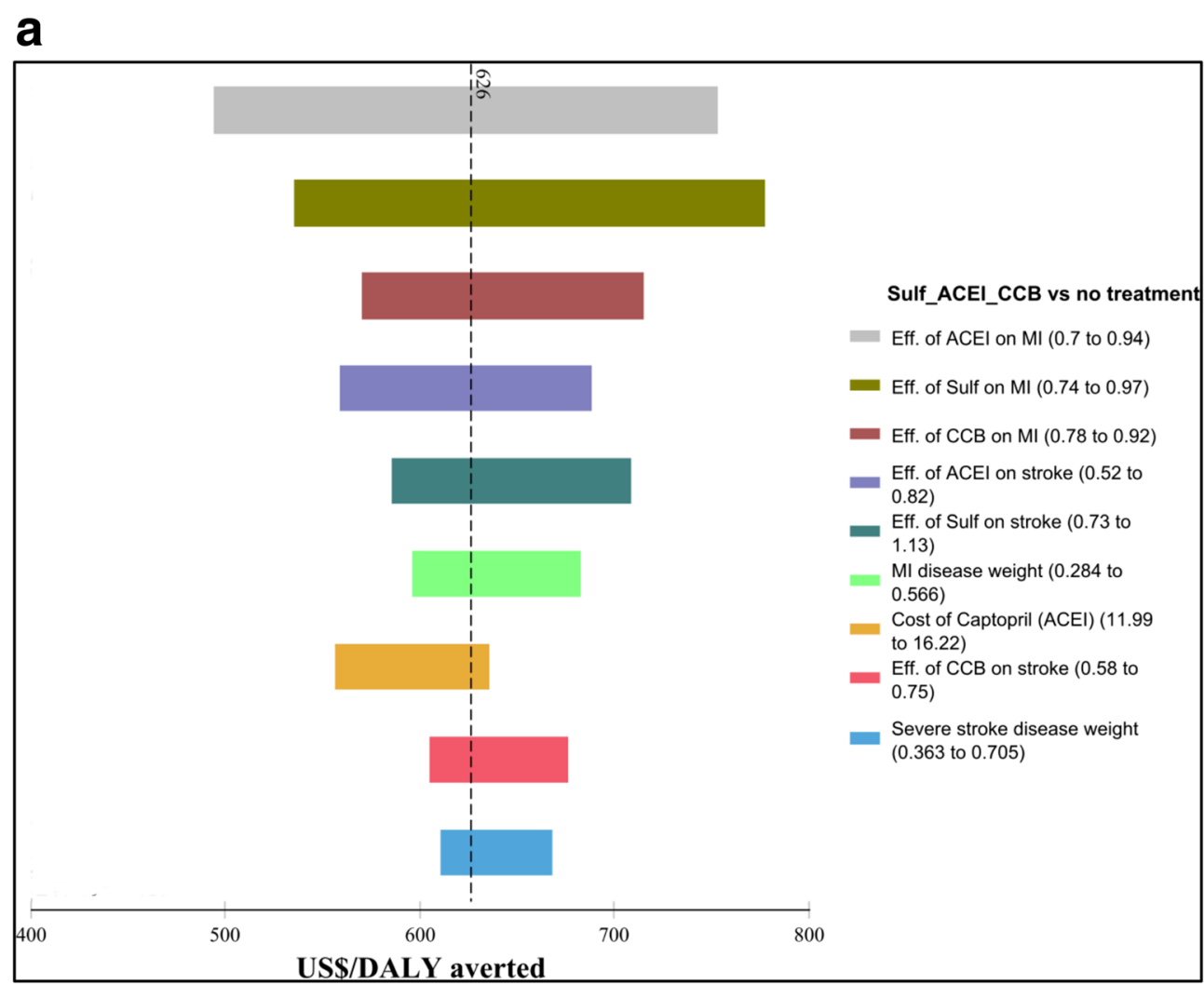

b

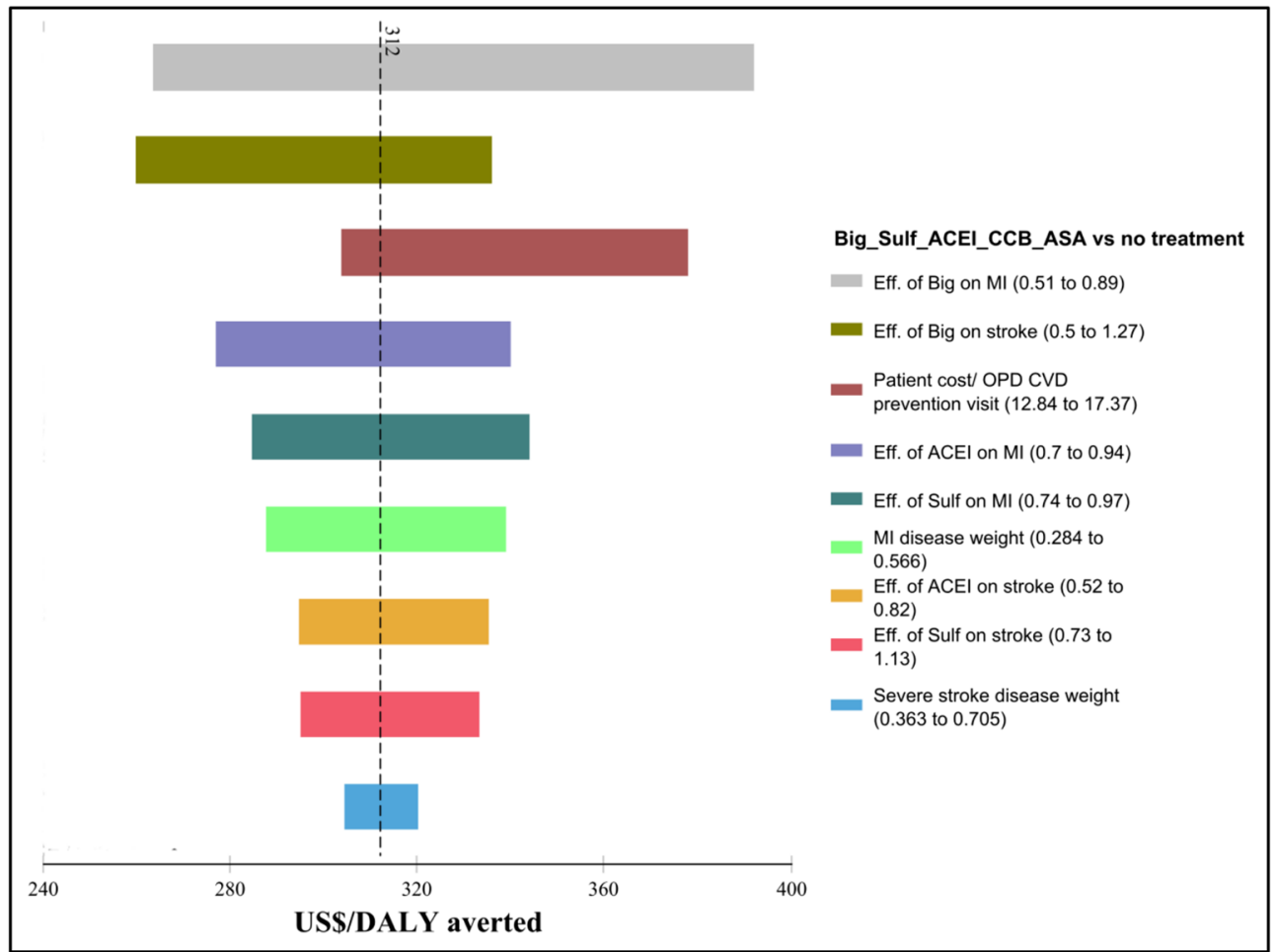

Fig. 2 ICER tornado diagrams for low and very high CVD risk with diabetes. a Low CVD risk with diabetes. b Very high CVD risk with diabetes 


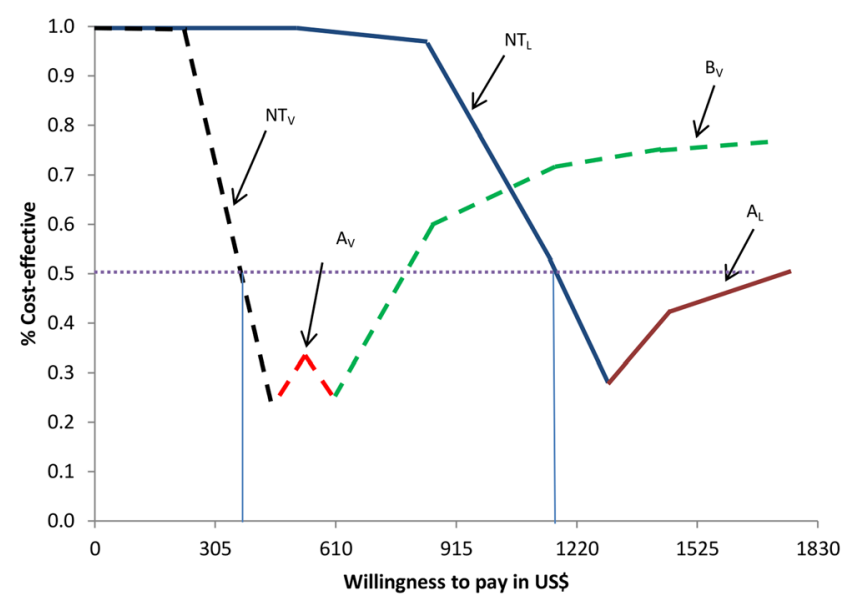

${ }^{1}$ Low CVD risk - represented by solid lines; ${ }^{2}$ Very high CVD risk - represented by dotted lines; $\mathrm{NT}_{\mathrm{L}}$ No treatment for the low-risk cohort; $\mathrm{A}_{\mathrm{L}}-\mathrm{ACEI}$ and Diu; $\mathrm{NT}_{\mathrm{v}}-$ No treatment for the very high-risk cohort; $\mathrm{A}_{\mathrm{V}}$ - ACEI, CCB, Diu and ASA; $\mathrm{B}_{\mathrm{V}}$ - ACEI, CCB, Diu, Sta and ASA.

Fig. 3 Cost-effectiveness acceptability frontier for low and very high CVD risk

interventions with highest probability of being costeffective, while all other alternatives are excluded.

CVD prevention is not likely to be cost-effective until WTP approaches US\$1327 and US\$498 per DALY averted in patients with low and very high CVD risk respectively. For low-risk patients, ACEI and Diu is optimal for all plausible levels of WTP higher than US $\$ 1327$ per DALY averted, while for very high-risk patients a combination of ACEI, CCB, Diu and ASA is most likely to be optimal within the WTP range of US\$498-US\$651 per DALY averted, after which a further addition of Sta becomes optimal.

For patients with diabetes, WTP values of about US $\$ 608$ and US $\$ 350$ for low and very high CVD risk, respectively are required for CVD prevention to be costeffective compared to CVD risk without diabetes. For low-risk patients, a combination of Sulf, ACEI and CCB is optimal for WTP values between US\$608 and

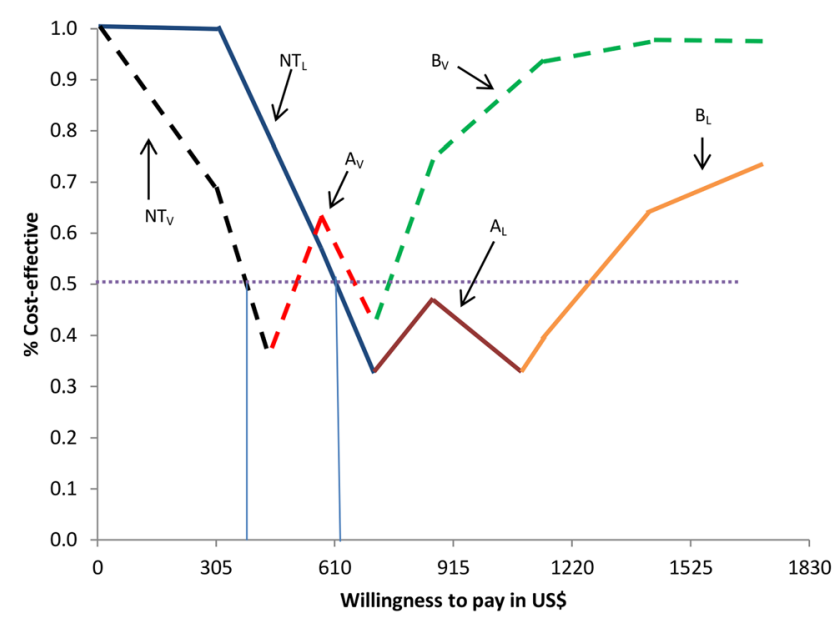

${ }^{1}$ Low CVD risk with diabetes - represented by solid lines; ${ }^{2}$ Very high CVD risk with diabetes represented by dotted lines; $\mathrm{NT}_{\mathrm{L}}$ - No treatment for low-risk cohort; $\mathrm{A}_{\mathrm{L}}$ - Sulf, $\mathrm{ACEI}$ and $\mathrm{CCB} ; \mathrm{B}_{\mathrm{L}}$ Big, Sulf ACEI and CCB; $\mathrm{NT}_{V}$ - No treatment for very high-risk cohort; $\mathrm{A}_{V}$ - Big, Sulf, ACEI, CCB and ASA; $B_{\mathrm{V}}$ - Big, Sulf, ACEI, CCB, ASA and Sta.

Fig. 4 Cost-effectiveness acceptability frontier for low and very high CVD risk with diabetes 
US\$958, followed by Big, Sulf, ACEI and CCB for a ceiling ratio exceeding US\$958. For very high-risk patients, a combination of Big, Sulf, ACEI, CCB and ASA is most likely to be optimal in the WTP range US\$350-US\$704 per DALY averted, after which the further addition of Sta becomes optimal.

The figures also illustrate that the above findings are surrounded by substantial uncertainty, except for patients with very high CVD risk and when WTP is very low (in which case no intervention is clearly optimal). For example, the ACEI and Diu combination in low-risk CVD patients without diabetes never exceeds a higher probability of being cost-effective than around $55 \%$, and consequently there is always at least a $45 \%$ probability of the preferred strategy being sub-optimal. For low-risk patients with diabetes, the corresponding numbers are $75 / 25 \%$ for the intervention Sulf, ACEI and CCB.

\section{Expected value of perfect information (EVPI) analysis}

Presented here are the EVPI analysis results for low and very high CVD risk without and with diabetes. The population EVPI-which represents the maximum amount of funds a decision-maker, should be willing to invest in research to eliminate all uncertainties-varied considerably with the different values of the WTP and risk levels (Appendix 6).

From Fig. 5 above, if Tanzanian's WTP is US\$610 then further research is potentially cost-effective for all risk levels except low CVD risk if the cost of proposed research is at most US\$160,000.

\section{Scenario analyses}

\section{Societal vs provider perspective}

CVD risk: There were some changes in optimal therapies when the model was re-analyzed with patient costs excluded. For example, Diu as monotherapy became optimal for low and moderate risk levels, with ICERs of US\$723 and US\$092 per DALY averted respectively, and there was a re-emergence of $\mathrm{BB}$ in the non-dominated drug combinations for all risk levels (Appendix 7).

CVD risk with diabetes: Model results remained largely the same for the CVD risk with diabetes model from the providers' perspective. We observed the strategies Sulf, ACEI and CCB being recommended for high-risk patients and Sulf, ACEI, CCB and ASA for very high-risk patients, whereas such combinations were dominated in our base case (Appendix 7).

In both CVD risk without and with diabetes, model results from the societal perspective generally had lower ICERs compared to those from the provider viewpoint.

\section{Differential vs non-differential discounting}

Whether or not health outcomes are to be discounted (and at what rate) has raised a lot of debate in the field of economic evaluation [41, 45-48]. Our base-case analysis was performed using non-differential discounting of $3 \%$ for costs and health outcomes. We applied differential discounting in two forms, a lower discount rate $(1.5 \%)$ and no discount rate for health outcomes, while keeping the discount rate for costs constant at $3 \%$. Lower discount rates for health outcomes reduce the ICERs, making CVD prevention more attractive, but model recommendations in terms of rank ordering of the alternatives did not change. With a lower or no discount rate for health outcomes, more costly yet more effective strategies become optimal for lower levels of WTP (Appendix 7).

\section{Different index cohort definition}

Our choice on index cohorts i.e. females for low risk and males for moderate to very high risk would imply that our main model results may not apply for males' low-risk patients and females' moderate to very high risks. We

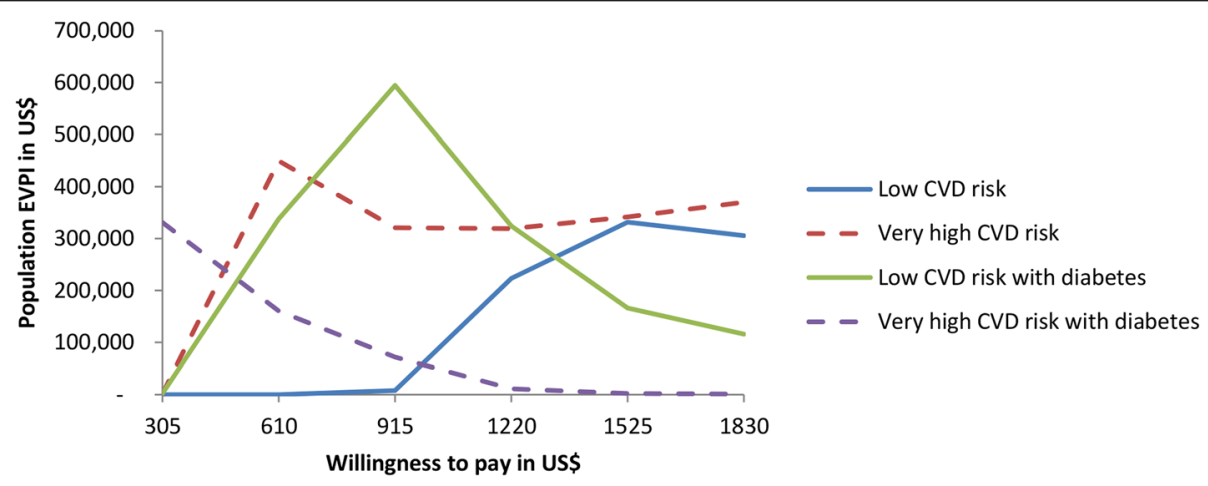

Fig. 5 Population EVPI curve for low and very high CVD risk without and with diabetes 
therefore constructed and re-run the model with a new set of index cohorts with the reverse gender and risk combinations (Appendix 8, Tables 11 and 12). The model conclusions remain robust in terms of rank ordering of the different drug combinations, but higher willingness to pay values are required in order to recommend interventions to female compared to male patients (Table 3 and Appendix 8, Table 13).

\section{Discussion}

This analysis suggests that multi-drug combinations achieve the best value for money for almost all risk levels both in the CVD risk and CVD risk with diabetes cohorts. If Tanzania is willing to pay up to US\$610-one Gross Domestic Product (GDP) per capita per DALY averted, below which interventions are considered to be very cost-effective by the WHO [38]-our model recommends no medical treatment for low-risk without diabetes patients. For a moderate risk level without diabetes, a combination of ACEI and Diu has an ICER that falls below the tentative WTP threshold value. Adding $\mathrm{CCB}$ to this combination was the optimal choice for high-risk patients, while for very high-risk patients further adding ASA is suggested. For patients with diabetes, a combination of Sulf, ACEI and CCB is predicted to be optimal for low and moderate risk levels while adding Big to this combination consistently yielded more health for money for high and very high risk levels. For very high-risk patients, ASA was also part of the combination.

These conclusions are in line with the WHO's CVD preventive guidelines, which recommend no medical management for low CVD risks [22]. We also observed similar results to those demonstrated in the costeffectiveness analysis of primary prevention of CVD in Australia, where they recommended Diu, CCB, ACEI and Sta for all patients with a $5 \% 5$-year CVD risk. The same conclusion cannot be drawn for our moderate-risk patients since we assumed that triple anti-hypertensives were not clinically relevant for this risk level.

Our results are different from those of a similar study performed in Tanzania [12], in which their recommended strategies, including combinations with $\mathrm{BB}$, are dominated in our work. Differences in study perspectives, cost evidence, clinical evidence and choice of interventions analyzed meant that differences in optimal interventions were not unlikely. For example, interventions modelled in this work restricted ASA to very highrisk patients only and included ACEI in the drug combinations, which is not the case in the previous study. Comparing our model recommendations to the WHOCHOICE study and a recent cost-effectiveness analysis to combat CVD in SSA and South East Asia results, we observed that drug combinations with Diu and BB were dominated and that our optimal strategies included combinations of ACEI with CCB or Diu. It is worth noticing that in these two studies only two antihypertensives, Diu and BB, were included, making comparability challenging $[13,49]$. It suffices to say that we observed a re-emergence of $\mathrm{BB}$ in the recommended interventions in the scenario analysis from a provider perspective. This viewpoint was followed both in the former Tanzanian and WHO-CHOICE studies, making our results somewhat similar if the provider perspective was applied as base-case.

Our literature search revealed no studies analyzing options to prevent CVD in patients with diabetes. So we compared our results for this cohort with the WHO's CVD guidelines, which recommend metformin (biguanide) as the oral hypoglycemic drug of choice. We find that glibenclamide (sulfonylureas) is optimal for low and moderate-risk patients, while adding metformin to glibenclamide is likely to be optimal for higher risk levels.

Our decision rule is based on the WHO's proposed cost-effectiveness threshold of one times GDP per capita for Tanzania. This is because of the lack of a ceiling ratio set by Tanzania's decision-makers. However, the use of WHO's recommended cost-effectiveness benchmarks of one and three times GDP per capita [38] has received some criticisms. The basis of this threshold is unclear; as such, it is not known whether it infers values based on previous decisions or is set to optimally determine or exhaust the healthcare budgets of some representative countries [50]. Its use tends to make "almost" all healthcare interventions and programmes seem cost-effective and does not reflect the reality of resource constraints, hence challenging countries to introduce virtually any costeffective interventions, which may end up with very low coverage and hence exacerbate healthcare inequalities [51]. Tanzania should preferably determine its own ceiling ratio by tailoring its recommendations to its own budgetary constraints, epidemiological and demographic profile, existing health infrastructure and other health-system considerations. Several approaches have been proposed to define the value of willingness to pay ceilings $[50,52,53]$.

Most cost-effectiveness guidelines recommend a provider perspective in order to inform decisions about efficient use of healthcare resources [54]. The societal perspective has also been proposed in some guidelines because it is more consistent with welfare economics. Whether it is possible to fully adopt a societal perspective in cost-effectiveness analysis has been discussed [54-56]. We do not claim to have adopted a broad societal perspective, but a rather "narrow" one since we only expanded the providers' perspective by including patient costs. The ICER results were more favourable from the societal than the provider perspective, which implies that ignoring patient costs could lead to sub-optimal 
resource allocation. It is equally true that including all relevant societal costs and benefits could significantly alter what we, in this work, consider to be very costeffective.

Assuming the WTP value of US $\$ 610$ and a proposed cost of research of about US\$250,000, there will be value for further information for very high CVD risk without diabetes and low CVD risk with diabetes since their population EVPI exceeds the estimates of the proposed research. Current information regarding low CVD risk without diabetes is deem sufficient given its microscopic population EVPI value. Further exploration is required to determine what type of additional evidence would be most valuable and the most efficient research design [44]. In practice, though, the value of research will be lower since some uncertainty will always remain.

\section{Strengths and limitations}

We adopt a "narrow" societal perspective in this study by taking into account patient costs. This viewpoint captures societal benefits that are not captured from more restricted viewpoints [56]. This work also analyzed interventions for all CVD risk levels, both without and with diabetes; although extensive, this permits comparisons within levels and between the two models for a better understanding of what does (or does not) work for each level of CVD risk.

These results should also be considered in light of model limitations. Firstly, the risk of myocardial infarction and stroke and drug treatment effects are based on data from trials carried out in developed countries, since good Tanzanian or regional data were unavailable. Secondly, effectiveness data for two drug classes (biguanide and glibenclamide) were extracted from one trial only, but again this was motivated by lack of data. Thirdly, we did not synthesize the evidence structure as we should have. Ideally, since most of our efficacy data were from trials with placebo as a comparator, indirect treatment comparisons (ITC) should have been performed and, in the very few instances where data was from other comparators, mixed treatment comparisons (MTC) should have been made. This weakness in inference concerning the relative efficacy of all treatments considered could possibly bias our results. However, these complex expansions of standard meta-analysis evidence are only as good as the trials included in them. Given the lack of a strong evidence base in our setting and since choices in healthcare resource allocation have to be made, we feel that our model results could, at this point, sufficiently inform these decisions [57]. Fourthly, we did not account for non-adherence to treatment in our model for reasons of simplification and lack of data, and our model may therefore not reflect real adherence in long-term treatment. Non-adherence would likely reduce the efficacy of the pharmacological drugs modelled, which would pull result in the direction of less favourable ICER estimates. On the other side, nonadherence represents cost savings, which would pull in the opposite direction. The overall effect on the estimates is an empirical question, but our intuition is that the former effect would weight more heavily, and that low adherence potentially would make ICERs somewhat less attractive. Lastly, we should expect the effectiveness values of our interventions to be lower in practice than the ones used in this work since the efficacy data are extracted from a "controlled" trial setting.

\section{Conclusion}

Multiple drug combinations as a means of preventive cardiology yield ICERs lower than the proposed ceiling ratio of one GDP per capita for all risk levels except low CVD risk, which renders them very cost-effective. However, our model conclusions are surrounded by high uncertainty regarding both whether or not to treat and optimal treatment choice. The results of the value of information analysis suggest that it is potentially costeffective to perform research to reduce uncertainties around model recommendations even at the lower WTP of US\$610. Decision-makers could therefore simultaneously adopt the model recommendations and consider further research, since the adoption decision is reversible. The fact that interventions are cost-effective given current information does not automatically mean that they should be recommended for implementation, since health systems usually have other recourse competing "very cost-effective" interventions that have not been fully implemented. There are also other objectives besides maximizing population health outcomes. Budget impact analysis and distributional concerns should be considered, for example, to assess governments' ability and to whom these benefits will accrue.

\section{Ethical statement}

Ethical clearance was provided by the Ethical Review Committee of the Tanzania National Institute of Medical Research with Ref. No. NIMR/HQ/R.8 a/Vol. IX/ 1364. Respondents from the health facilities involved were asked for their consent to participate in the study and written permission was obtained prior to the interviews.

\section{Availability of data and materials}

The datasets supporting the conclusions of this article are included within the article and its appendices. 


\section{Appendices}

\section{Appendix 1}

Cost-effectiveness model

The CVD prevention model is a probabilistic Markov model that provides information on health and healthcare costs over the lifetime of a hypothetical Tanzanian population (or population sub-groups). Two Markov decision models for CVD risk without diabetes and CVD risk with diabetes were constructed using TreeAge Pro 2014 software (Figure 6) for four CVD risk cohorts. Modelling them separately was necessary since CVD have different risk and treatment profiles depending on whether or not the patient is diabetic.
Six mutually exclusive health states were considered: "no history of CVD" (i.e. no previous myocardial infarction or stroke), "history of myocardial infarction", and "history of stroke". Finally, "death" was modelled as an absorbing state. Stroke was modelled in three different health states based on severity: "mild", "moderate" or "severe", in order to be consistent with disability weights reported in the GBD 2010 [26].

A cohort of healthy individuals with "no history of CVD" first enters the model at the age of 40 years. The cohort then transits between the different health states according to age-specific risks for each type of clinical event and depending on the risk reduction from the alternative preventive drugs. Each type of health state

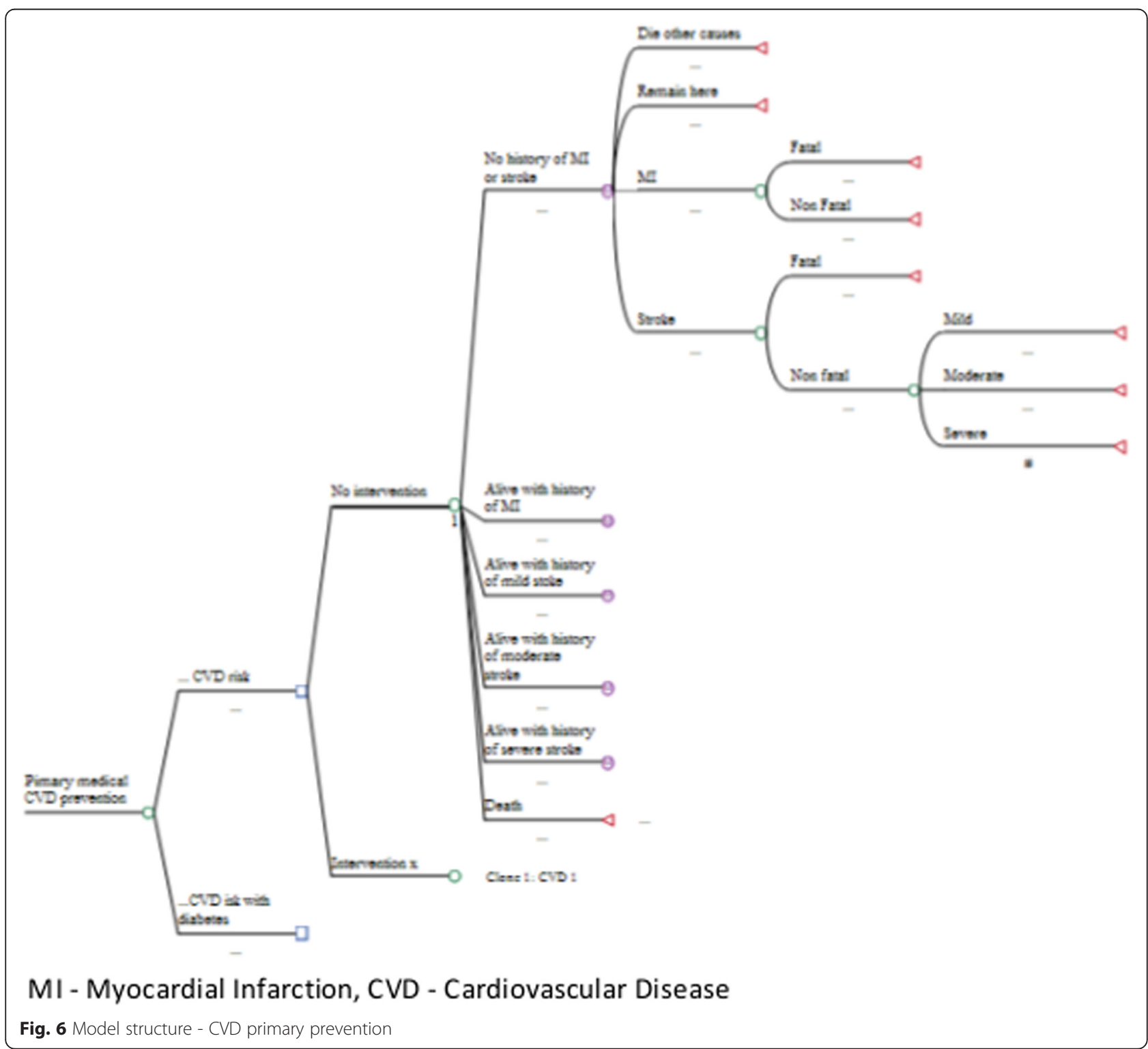


Table 4 Base case index cohort's characteristics according to CVD risk levels

\begin{tabular}{|c|c|c|c|c|}
\hline Index cohort & Low risk & Moderate risk & High risk & Very high risk \\
\hline \multicolumn{5}{|l|}{ Without diabetes } \\
\hline Total cholesterol & $4 \mathrm{mmol}$ & $>8 \mathrm{mmol}$ & $>8 \mathrm{mmol}$ & $>8 \mathrm{mmol}$ \\
\hline Systolic blood pressure & $120-139 \mathrm{mmHg}$ & $140-159 \mathrm{mmHg}$ & 160-179 mmHg & $160-179 \mathrm{mmHg}$ \\
\hline Smoking & No & No & No & Yes \\
\hline Sex & Female & Male & Male & Male \\
\hline \multicolumn{5}{|l|}{ With diabetes } \\
\hline Total cholesterol & $4 \mathrm{mmol}$ & $7 \mathrm{mmol}^{1}$ & $6 \mathrm{mmol}^{2}$ & $>8 \mathrm{mmol}$ \\
\hline Systolic blood pressure & $120-139 \mathrm{mmHg}$ & $140-159 \mathrm{mmHg}$ & $160-179$ mmHg & $160-179 \mathrm{mmHg}$ \\
\hline Smoking & No & No & No & Yes \\
\hline Sex & Female & Male & Male & Male \\
\hline
\end{tabular}

Age groups were: 40-49, 50-59, 60-69, 70-79, 80-89 and 90-99 (Appendix 3 Table 5); ${ }^{1} 6 \mathrm{mmol}$ and 5 mmol used for age group 60-69 and age groups > 70 years respectively; ${ }^{2} 5 \mathrm{mmol}$ used for age groups $>70$ years

incurs costs and changes in health outcomes which are re-calculated after every annual cycle. A 60-year time horizon was considered to reflect the chronic nature of CVD.

In each model, "no treatment" was the baseline strategy and was compared with different medical interventions (singly or in combination) for primary prevention of CVD. The inclusion of "no treatment" as a comparator was important to allow for low-risk groups for whom treatment is not likely to be cost-effective. In order to explore the effects of the interventions in different populations, four distinct submodels were created to represent four CVD risk levels: low risk, moderate risk, high risk and very high risk with a 10-year risk of CVD event of $<10 \%, 10$ $19 \%, 20-30 \%$ and $>30 \%$ respectively.

\section{Appendix 2}

Figure 7 presents the strategies analyzed in the CVD model diagrammatically. For low and moderate CVD risk, the strategies modelled are represented by "Package LM", which consists of individual anti-hypertensives $\mathrm{ACEI}, \mathrm{ARB}, \mathrm{BB}, \mathrm{CCB}$ and Diu in mono and duotherapy as shown by the inner circle in the diagram under the label "Low and moderate risk". Package LM is then combined with statin, e.g. ACEI + statin, $\mathrm{ACEI}+\mathrm{ARB}+$ statin etc. represented by the "statin circle" embedded in the inner circle. Third, statin alone is also analyzed for this risk level and lastly "no treatment" option is also included, making a total of 32 interventions modelled.

Interventions modelled for high risk consist of: (i) All the interventions under Package LM, i.e. the 15 anti-hypertensives in mono and duo therapy, (ii) "Package $\mathrm{H}$ " which is anti-hypertensives in triple therapy - a total of 10 options, (iii) Package LM and Package $\mathrm{H}$ combined with statin, e.g. ACEI + statin, ACEI + ARB + statin, $\mathrm{ACEI}+\mathrm{ARB}+\mathrm{BB}+$ statin. (iv) No treatment option. Fifty-one (51) interventions were analyzed for this risk level.

Lastly, strategies considered for very high-risk patients are interventions analyzed under Package LM and Package $\mathrm{H}$ but now combined with soluble aspirin, e.g. ACEI $+\mathrm{ASA}, \quad \mathrm{ACEI}+\mathrm{ARB}+\mathrm{ASA}, \quad \mathrm{ACEI}+\mathrm{ARB}+\mathrm{BB}+\mathrm{ASA}$, represented by the inner circle with "ASA circle" embedded within it in the diagram under "Very high risk". These interventions are marked "Package VH". All these combinations are then combined with statin, e.g. $\mathrm{ACEI}+\mathrm{ASA}+$ statin, $\mathrm{ACEI}+\mathrm{ARB}+\mathrm{ASA}+$ statin, $\mathrm{ACEI}+$ $\mathrm{ARB}+\mathrm{BB}+\mathrm{ASA}+$ statin. With the no treatment option, the strategies made up a total of 51 interventions modelled.

The same approach can be used to interpret these diagrams, indicating the interventions analyzed for the four levels of CVD risk with diabetes. A total of 43 interventions were modelled for low and moderate CVD with diabetes risk levels while the number was 49 options for high and very high CVD with diabetes risk levels.

As depicted in Figure 8, drug combinations considered in the analysis consisted of up to two antihypertensives together with other drug classes for low and moderate risks. For these levels we assumed that combinations of three anti-hypertensives are clinically irrelevant. All other possible combinations without and with soluble aspirin were modelled for high and very high risks respectively. Soluble aspirin was included only for very high-risk patients, where it has been shown to be more beneficial than harmful [22]. 


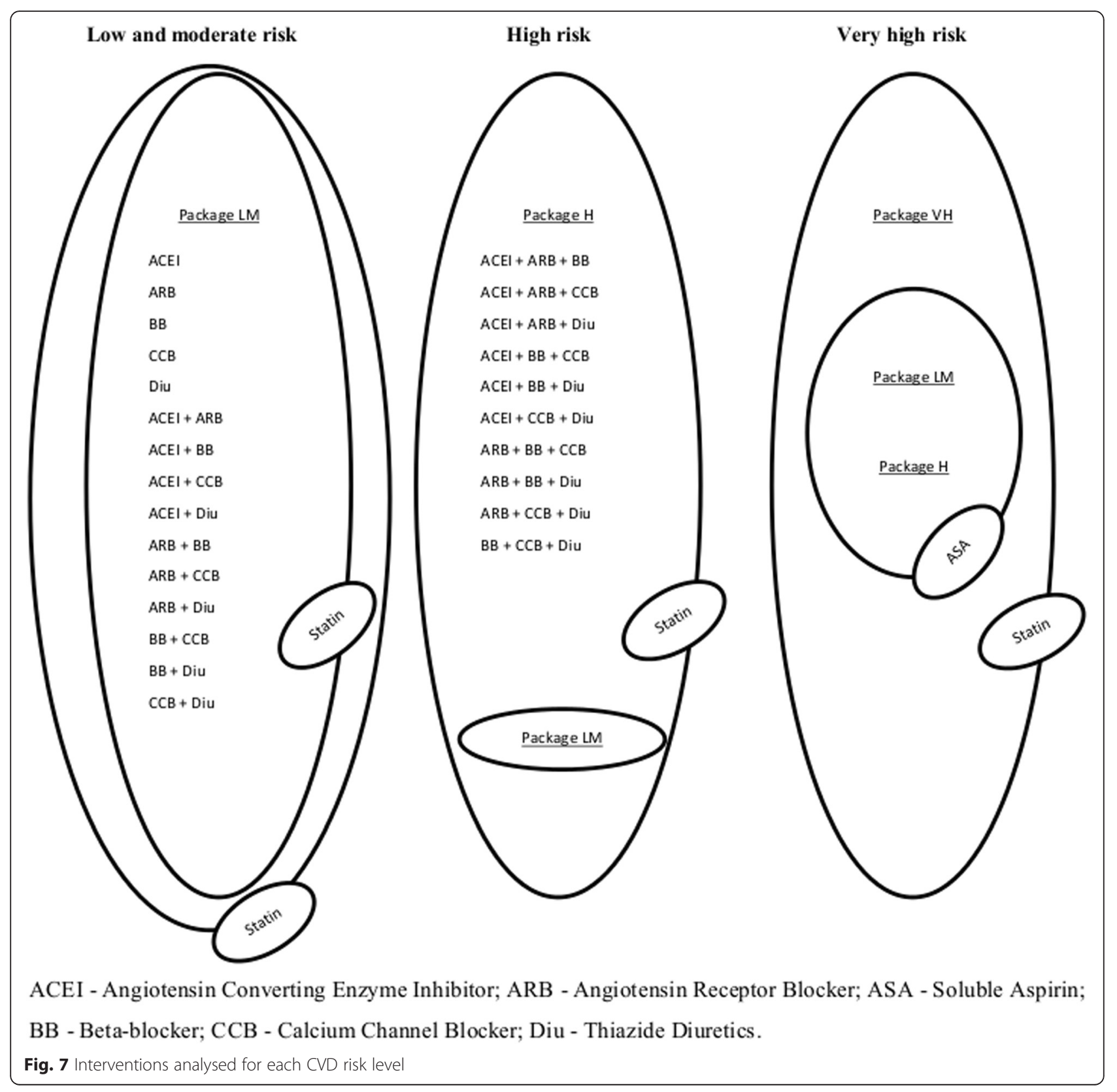




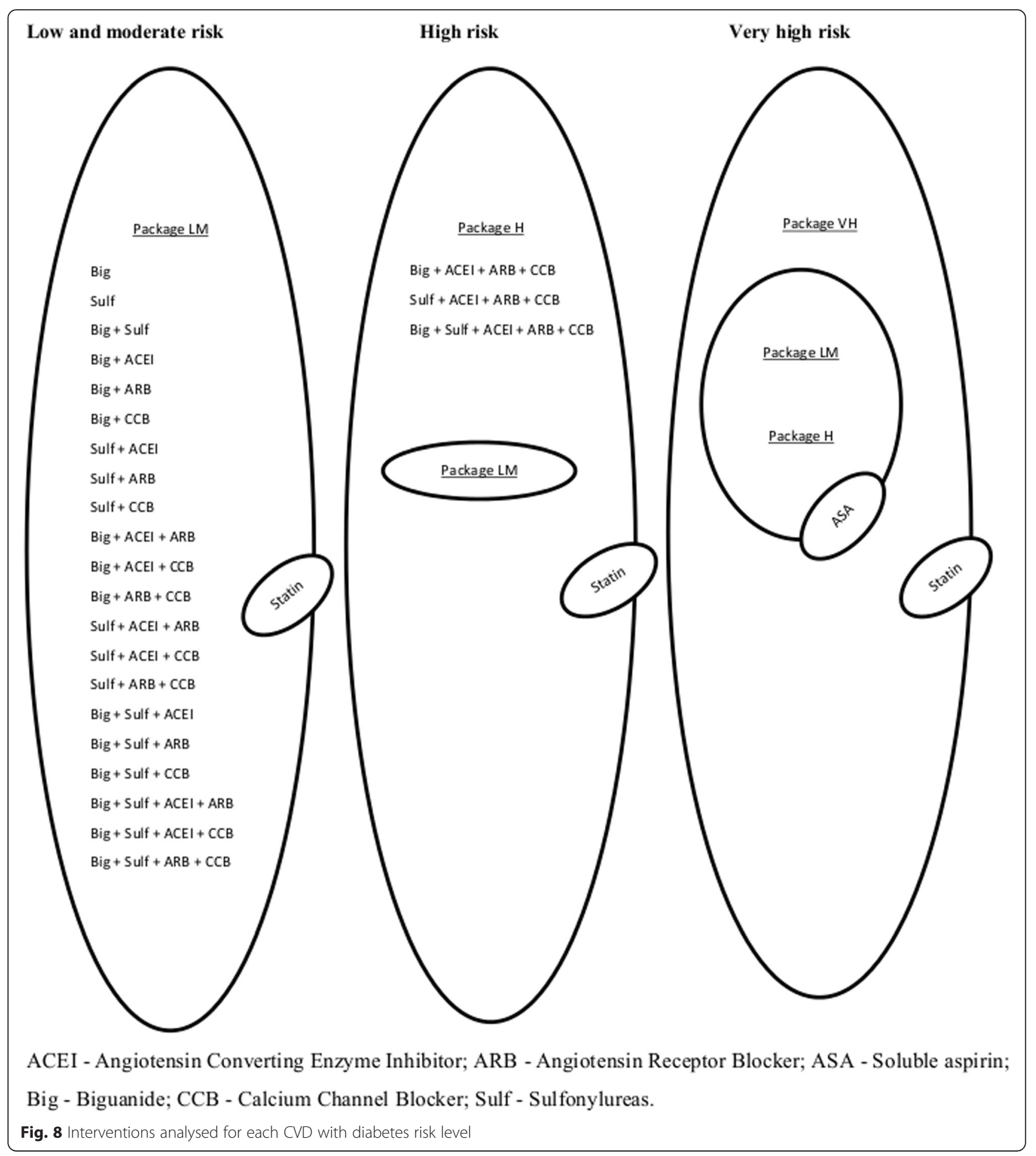




\section{Appendix 3}

Table 5 Annual risk of acute myocardial infarction and stroke, background mortality and case fatality rates

No previous history of acute myocardial infarction (AMI) or stroke CVD risk

\begin{tabular}{lll} 
& \multicolumn{2}{l}{ Acute myocardial infarction } \\
Age & Low & Moderate \\
$40-49$ & 0.0020 & 0.0130 \\
$50-59$ & 0.0040 & 0.0190 \\
$60-69$ & 0.0060 & 0.0290 \\
$70-79$ & 0.0060 & 0.0360 \\
$80-89$ & 0.0070 & 0.0390 \\
$90-99$ & 0.0080 & 0.0440
\end{tabular}

$\begin{array}{ll}\text { High } & \text { Very high } \\ 0.0160 & 0.0230 \\ 0.0230 & 0.0310 \\ 0.0310 & 0.0400 \\ 0.0380 & 0.0440 \\ 0.0430 & 0.0520 \\ 0.0480 & 0.0570\end{array}$

Stroke

CVD risk with diabetes

$\begin{array}{lll}40-49 & 0.0050 & 0.0140 \\ 50-59 & 0.0080 & 0.0210 \\ 60-69 & 0.0120 & 0.0270 \\ 70-79 & 0.0130 & 0.0290 \\ 80-89 & 0.0140 & 0.0350 \\ 90-99 & 0.0160 & 0.0390\end{array}$

$\begin{array}{ll}0.0140 & 0.0290 \\ 0.0210 & 0.0380 \\ 0.0290 & 0.0440 \\ 0.0310 & 0.0460 \\ 0.0370 & 0.0570 \\ 0.0430 & 0.0620\end{array}$

$\begin{array}{ll}\text { Low } & \text { Moderate } \\ 0.0020 & 0.0050 \\ 0.0020 & 0.0050 \\ 0.0040 & 0.0070 \\ 0.0060 & 0.0110 \\ 0.0110 & 0.0170 \\ 0.0190 & 0.0190\end{array}$

$\begin{array}{ll}\text { High } & \text { Very high } \\ 0.0060 & 0.0100 \\ 0.0070 & 0.0110 \\ 0.0100 & 0.0150 \\ 0.0150 & 0.0220 \\ 0.0220 & 0.0330 \\ 0.0360 & 0.0460\end{array}$

With previous history of AMl or stroke

CVD risk

\begin{tabular}{|c|c|c|c|c|c|c|c|c|}
\hline \multirow[b]{2}{*}{ Age } & \multicolumn{4}{|c|}{ Acute myocardial infarction } & \multicolumn{4}{|l|}{ Stroke } \\
\hline & Low & Moderate & High & Very high & Low & Moderate & High & Very high \\
\hline $40-49$ & 0.0021 & 0.0143 & 0.0184 & 0.0276 & 0.0023 & 0.0059 & 0.0072 & 0.0133 \\
\hline $50-59$ & 0.0042 & 0.0209 & 0.0265 & 0.0372 & 0.0023 & 0.0059 & 0.0084 & 0.0146 \\
\hline $60-69$ & 0.0063 & 0.0319 & 0.0357 & 0.0480 & 0.0045 & 0.0082 & 0.0120 & 0.0200 \\
\hline 70-79 & 0.0063 & 0.0396 & 0.0437 & 0.0528 & 0.0068 & 0.0129 & 0.0180 & 0.0293 \\
\hline $80-89$ & 0.0074 & 0.0429 & 0.0495 & 0.0624 & 0.0124 & 0.0199 & 0.0264 & 0.0439 \\
\hline $90-99$ & 0.0084 & 0.0484 & 0.0552 & 0.0684 & 0.0215 & 0.0222 & 0.0432 & 0.0612 \\
\hline \multicolumn{9}{|c|}{ CVD risk with diabetes } \\
\hline $40-49$ & 0.0053 & 0.0154 & 0.0161 & 0.0348 & 0.0034 & 0.0070 & 0.0096 & 0.0173 \\
\hline $50-59$ & 0.0084 & 0.0231 & 0.0242 & 0.0456 & 0.0045 & 0.0082 & 0.0120 & 0.0200 \\
\hline $60-69$ & 0.0126 & 0.0297 & 0.0334 & 0.0528 & 0.0068 & 0.0117 & 0.0156 & 0.0266 \\
\hline $70-79$ & 0.0137 & 0.0319 & 0.0357 & 0.0552 & 0.0124 & 0.0176 & 0.0240 & 0.0386 \\
\hline $80-89$ & 0.0147 & 0.0385 & 0.0426 & 0.0684 & 0.0215 & 0.0257 & 0.0348 & 0.0559 \\
\hline $90-99$ & 0.0168 & 0.0429 & 0.0495 & 0.0744 & 0.0362 & 0.0339 & 0.0420 & 0.0838 \\
\hline \multicolumn{9}{|c|}{ Case Fatality rate } \\
\hline & \multicolumn{2}{|c|}{ Acute myocardial infarction } & \multicolumn{2}{|l|}{ Stroke } & \multicolumn{4}{|c|}{ Background mortality } \\
\hline Age & Males & Females & Males & Females & Age & & & \\
\hline $40-49$ & 0.3040 & 0.4070 & 0.3470 & 0.3520 & $40-49$ & 0.0112 & & \\
\hline $50-59$ & 0.3110 & 0.4120 & 0.2480 & 0.1980 & $50-59$ & 0.0120 & & \\
\hline $60-69$ & 0.3360 & 0.4300 & 0.2830 & 0.2520 & $60-69$ & 0.0225 & & \\
\hline 70-79 & 0.3670 & 0.4510 & 0.4200 & 0.4120 & $70-79$ & 0.0467 & & \\
\hline 80-89 & 0.4090 & 0.4840 & 0.6420 & 0.6650 & 80-89 & 0.1006 & & \\
\hline 90-99 & 0.4510 & 0.5170 & 0.7920 & 0.8150 & $90-99$ & 0.1458 & & \\
\hline
\end{tabular}


Table 6 Intervention effects, costs, disability weights and other transition probabilities

\begin{tabular}{|c|c|c|c|}
\hline \multirow{2}{*}{$\begin{array}{l}\text { Parameter } \\
\text { a. Intervention effects and costs }\end{array}$} & \multicolumn{2}{|c|}{ Model input§ (95\% Cl) } & \multirow[t]{2}{*}{ Source } \\
\hline & & & \\
\hline \multicolumn{4}{|c|}{ Angiotensin converting enzyme inhibitor } \\
\hline \multirow[t]{2}{*}{$\mathrm{RR}^{1}$} & $M 1^{2}$ & $0.81(0.70-0.94)$ & \multirow[t]{2}{*}[58]{} \\
\hline & Stroke & $0.65(0.52-0.82)$ & \\
\hline $\operatorname{Cost}^{3}$ & & 14.10 & {$[59]$} \\
\hline \multicolumn{4}{|l|}{ Angiotensin receptor blocker } \\
\hline \multirow[t]{2}{*}{ RR } & $\mathrm{Ml}$ & $0.94(0.85-1.03)$ & \multirow[t]{2}{*}[60]{} \\
\hline & Stroke & $0.91(0.85-0.98)$ & \\
\hline Cost & & 64.83 & {$[59]$} \\
\hline \multicolumn{4}{|l|}{ Beta-blocker } \\
\hline \multirow[t]{2}{*}{ RR } & $\mathrm{Ml}$ & $0.90(0.78-1.03)$ & \multirow[t]{2}{*}[58]{} \\
\hline & Stroke & $0.83(0.72-0.97)$ & \\
\hline Cost & & 6.82 & {$[59]$} \\
\hline \multicolumn{4}{|l|}{ Biguanide } \\
\hline \multirow[t]{2}{*}{ RR } & $\mathrm{Ml}$ & $0.67(0.51-0.89)$ & \multirow[t]{2}{*}{ [61] } \\
\hline & Stroke & $0.80(0.50-1.27)$ & \\
\hline Cost & & 21.15 & {$[59]$} \\
\hline \multicolumn{4}{|l|}{ Calcium channel blocker } \\
\hline \multirow[t]{2}{*}{$\mathrm{RR}$} & $\mathrm{Ml}$ & $0.85(0.78-0.92)$ & \multirow[t]{2}{*}[62]{} \\
\hline & Stroke & $0.66(0.58-0.75)$ & \\
\hline Cost & & 13.19 & {$[59]$} \\
\hline \multicolumn{4}{|l|}{ Soluble Aspirin } \\
\hline \multirow[t]{2}{*}{$\mathrm{RR}$} & $\mathrm{Ml}$ & $0.77(0.69-0.86)$ & \multirow[t]{2}{*}{ [63] } \\
\hline & Stroke & $0.95(0.85-1.06)$ & \\
\hline Cost & & 14.79 & [59] \\
\hline \multicolumn{4}{|l|}{ Statin } \\
\hline \multirow[t]{2}{*}{$\mathrm{RR}$} & $\mathrm{Ml}$ & $0.86(0.82-0.90)$ & \multirow[t]{2}{*}[64]{} \\
\hline & Stroke & $0.90(0.85-0.95)$ & \\
\hline Cost & & 15.92 & {$[59]$} \\
\hline \multicolumn{4}{|l|}{ Sulfonylureas } \\
\hline \multirow[t]{2}{*}{$\mathrm{RR}$} & $\mathrm{Ml}$ & $0.85(0.74-0.97)$ & {$[61]$} \\
\hline & Stroke & $0.91(0.73-1.13)$ & \\
\hline Cost & & 6.37 & {$[59]$} \\
\hline Thiazide diuretics & & & \\
\hline RR & $\mathrm{Ml}$ & $0.84(0.75-0.95)$ & {$[58]$} \\
\hline & Stroke & $0.63(0.57-0.71)$ & \\
\hline Cost & & 1.18 & [59] \\
\hline b. Costs & & & \\
\hline Cost of $\mathrm{CVD}^{4}$ prevention & & & \\
\hline Patient cost per OPD ${ }^{5}$ visit & & 15.1 & [34] \\
\hline Provider cost per OPD visit & & 7.15 & \\
\hline Provider cost per lab test & & 4.07 & \\
\hline
\end{tabular}


Table 6 Intervention effects, costs, disability weights and other transition probabilities (Continued)

\begin{tabular}{|c|c|c|c|c|c|}
\hline \multicolumn{6}{|l|}{ Cost of CVD treatment } \\
\hline \multirow[t]{2}{*}{ Patient cost per CVD treatment } & & \multicolumn{3}{|l|}{194} & \multirow[t]{2}{*}{ [35] } \\
\hline & $\mathrm{Ml}$ & Mild stroke & Mod. ${ }^{6}$ stroke & Sev. ${ }^{7}$ stroke & \\
\hline CVD risk - first year & 310 & 271 & 512 & 570 & \multirow[t]{4}{*}{ Estimation } \\
\hline CVD risk - subsequent years & 260 & 67 & 76 & 313 & \\
\hline CVD risk with diabetes - first year & 358 & 319 & 560 & 594 & \\
\hline CVD risk with diabetes - subsequent years & 308 & 115 & 124 & 361 & \\
\hline \multicolumn{6}{|l|}{ c. Disability weights ${ }^{8}$} \\
\hline Acute MI & & $0.42(0.28-0.57)$ & & & \multirow[t]{4}{*}{ [26] } \\
\hline Mild stroke & & $0.02(0.01-0.04)$ & & & \\
\hline Moderate stroke & & $0.08(0.05-0.11)$ & & & \\
\hline Severe stroke & & $0.54(0.36-0.71)$ & & & \\
\hline \multicolumn{6}{|l|}{ d. Other probabilities } \\
\hline \multicolumn{6}{|l|}{ In the event of a first ever stroke, } \\
\hline \multicolumn{6}{|l|}{ what is the probability of a: } \\
\hline mild stroke for a CVD risk & & 0.19 & & & {$[65,66]$} \\
\hline moderate for a CVD risk & & 0.44 & & & Extrapolation \\
\hline severe for a CVD risk & & 0.27 & & & and \\
\hline mild stroke for a CVD risk with diabetes & & 0.15 & & & assumptions \\
\hline moderate for a CVD risk with diabetes & & 0.35 & & & \\
\hline severe for a CVD risk with diabetes & & 0.50 & & & \\
\hline \multicolumn{6}{|l|}{ In the event of a subsequent stroke, } \\
\hline \multicolumn{6}{|l|}{ what is the probability of: } \\
\hline ...mild stroke & & 0.15 & & & \\
\hline ...moderate stroke & & 0.25 & & & \\
\hline .... severe stroke & & 0.60 & & & \\
\hline
\end{tabular}

${ }^{1}$ RR - Relative risk with beta distribution fitted; ${ }^{2} \mathrm{MI}$ - Myocardial in arction; ${ }^{3}$ Cost - All costs are in 2012 US\$ and were fitted with a gamma distribution; ${ }^{4} \mathrm{CVD}$ Cardiovascular disease; ${ }^{5} \mathrm{OPD}$ - Out-patient department; ${ }^{6}$ Mod. - Moderate; ${ }^{7}$ Sev. - Severe; ${ }^{8}$ Beta distribution was fitted disability weights and other probabilities; §All model parameters were varied at $\pm 15 \%$ unless stated; $\uparrow$ provider cost per OPD visit is the average cost per visit for the four facilities costed, provider cost per lab test available from Table 5, Patient cost per OPD visit was derived from annual patient cost divided by average number of clinic visits [34]. 


\section{Appendix 4}

Table 7 Summary of meta-analyses and individual trials from which intervention effects were extracted

\begin{tabular}{|c|c|c|c|c|c|c|c|}
\hline Drug class & Trials & Drug names & Comparator & Type & Blinded & Statistical method & Notes \\
\hline \multirow[t]{2}{*}{$\overline{\mathrm{ACEl}}$} & 3 & Ramipril, Deserpidine, & Placebo & MA & Double* & $\mathrm{RR}, \mathrm{M}-\mathrm{H}$, fixed, $\mathrm{Chi}^{2}$ & $72 \%$ PP \\
\hline & & Perindopril, Captopril & & & & & \\
\hline \multirow[t]{2}{*}{ ARB } & 17 & Cardisartan, Valsartan, & Placebo & MA & $N R \sim$ & $\mathrm{RR}$, random, fixed, $\mathrm{I}^{2}$ & NR \\
\hline & & $\begin{array}{l}\text { Irbesartan, Telmisartan, } \\
\text { Lorsartan }\end{array}$ & & & & & \\
\hline ASA & 6 & Soluble aspirin & Placebo $^{1}$ & MA & Blinded \{ & Rate ratio, NS, $X^{2}$ & PP trials only \\
\hline BB & 5 & Propanolol, Atenolol & Placebo & MA & Double§ & RR, M-H, fixed, $\mathrm{Chi}^{2}$ & $72 \%$ PP \\
\hline Big & 1 & Metformin & Conventional therapy & RCTs & No & NA & NA \\
\hline$C C B$ & 22 & $N R$ & Placebo & MA & Doublet & RR, M-H, fixed, Chi ${ }^{2}$ & $N R$ \\
\hline \multirow[t]{2}{*}{ Diu } & 19 & $\begin{array}{l}\text { Indapamide, CHTD, } \\
\text { Chlorothiazide, }\end{array}$ & Placebo & MA & Double & RR, M-H, fixed, $\mathrm{Chi}^{2}$ & $72 \%$ PP \\
\hline & & $\begin{array}{l}\mathrm{HCTZ} \text {, Bendrofluazide, } \mathrm{T} \\
\text { richloromethiazide }\end{array}$ & & & & & \\
\hline \multirow[t]{2}{*}{ Sta } & 10 & Pravastatin, Lovastatin, & Placebo, $U C^{2}$ or diet $^{3}$ & MA & Doubleł & OR, random, fixed, $I^{2}$ & $\begin{array}{l}80 \% \text { PP or separate } \\
\text { note on PP }\end{array}$ \\
\hline & & $\begin{array}{l}\text { Artorvastatin, } \\
\text { Simvastatin, Rosuvastatin }\end{array}$ & & & & & \\
\hline Sulf & 1 & Sulfonylureas-insulin & Conventional therapy & RCTs & No & NA & NA \\
\hline
\end{tabular}

ACEI - Angiotensin Converting Enzyme Inhibitor, ARB - Angiotensin Receptor Blocker, Asp - Soluble Aspirin, BB - Beta Blocker, Big - Biguanide, CCB - Calcium Channel Blocker, Diu - Diuretic, Sta - Statins, Sulf - Sulfonylureas, CHTD - Chlorothalidone, HCTZ - Hydrochlorothiazide, UC - usual care, MA - Meta analyses, RCTs Randomized Controlled Trials, NR - Not reported, RR - Relative risk, M-H - Mantel Haenszel, OR - Odds ratio, PP - Primary prevention, SP - Secondary prevention, NA - Not applicable, 22- - These are trials which reported MI events; 9 reported stroke events, Double* - two trials were open label, NR - Even though blinding was not reported it was considered in trial quality, Placebo1 - Two trials compared aspirin with no comparator and open-label vitamin E, Blinded - Two trials were open trials, Double§ - One trial was single blinded and one open trial, Doublet - One trial was not blinded, Double - Four trials were single blinded and three trials were open, Double - Blinding status was not reported for one trial. For those drug classes which were not compared with placebo, we assume that comparability between different drug classes remains valid since a non- pharmacological agent was used. Ideally a mixed treatment comparison analysis should have been performed with all the drug classes whose comparator was not a placebo 


\section{Appendix 5}
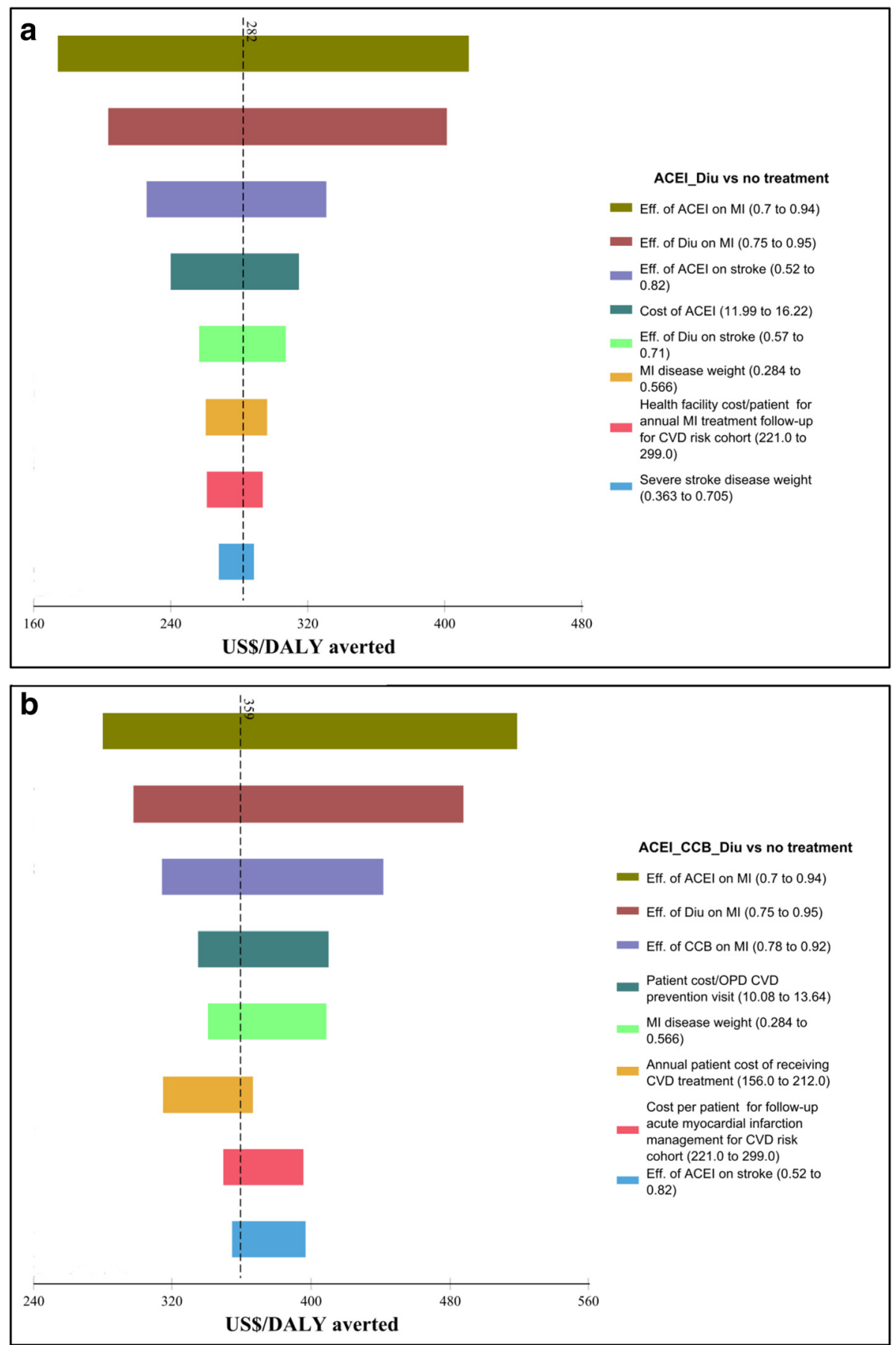

Fig. 9 ICER tornado diagrams for moderate and high CVD risk. a Moderate CVD risk. b High CVD risk 

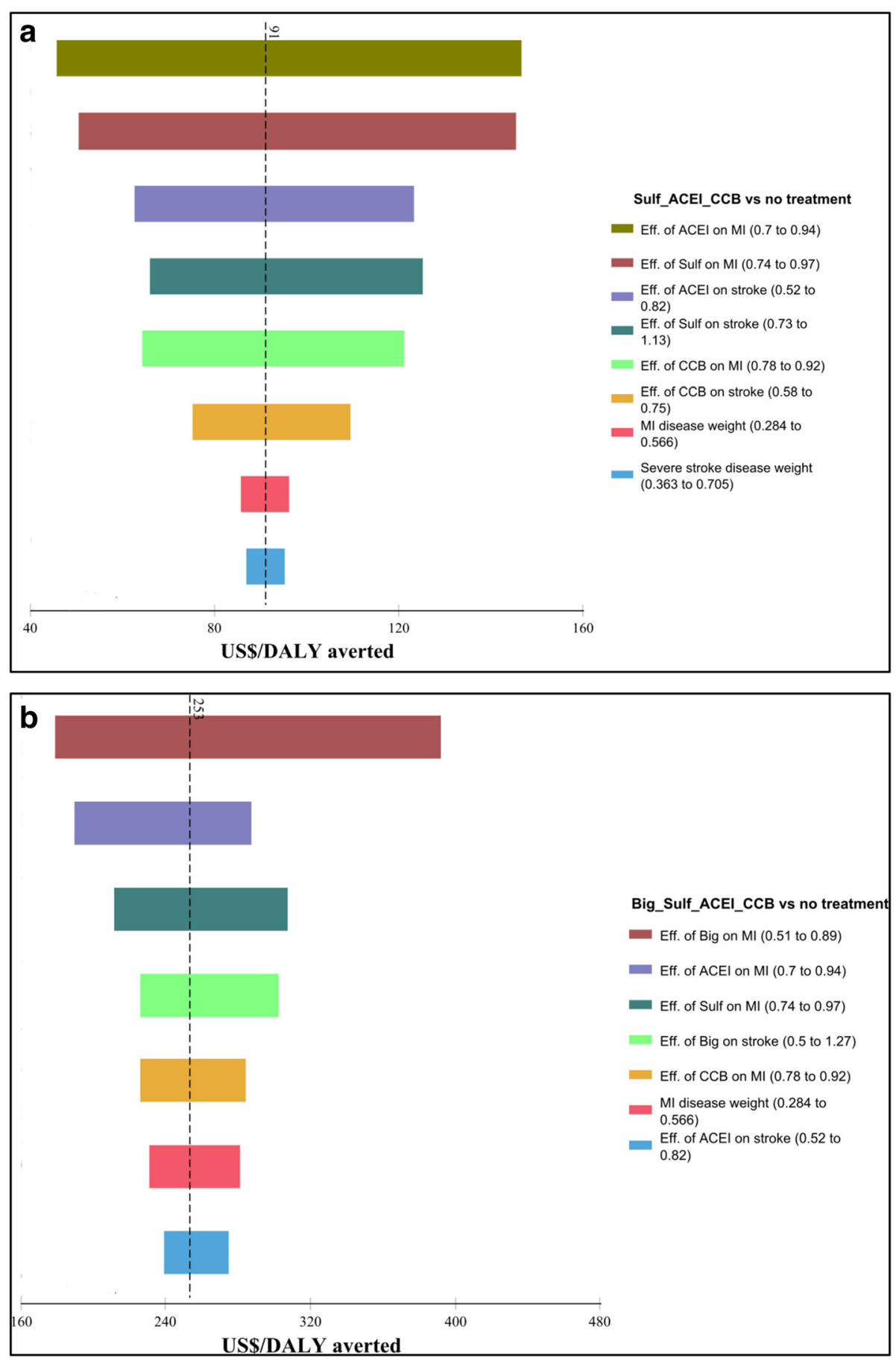

Fig. 10 ICER tornado diagrams for moderate and high CVD risk with diabetes. a Moderate CVD risk with diabetes. b High CVD risk with diabetes 


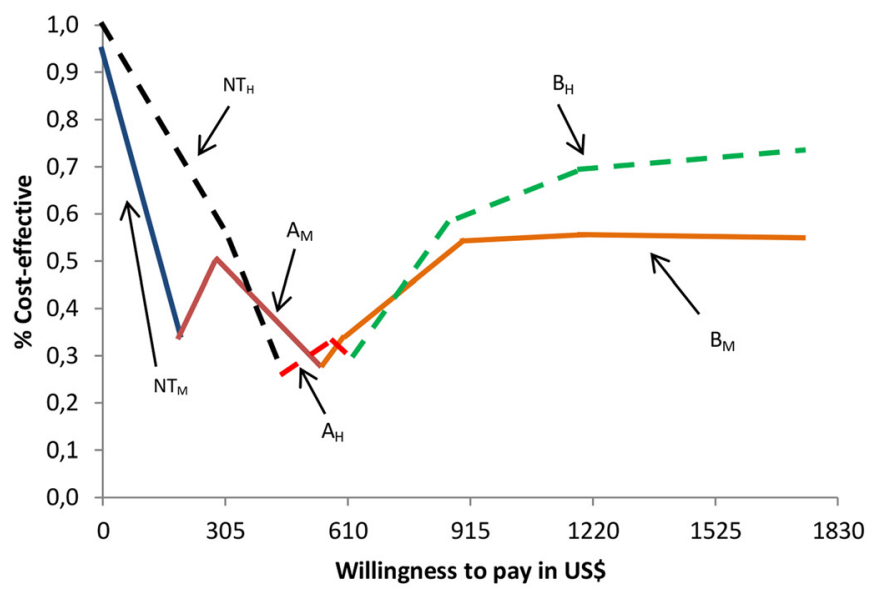

${ }^{1}$ Moderate CVD risk - represented by solid lines; ${ }^{2}$ High CVD risk - represented by dotted lines; $\mathrm{NT}_{\mathrm{M}}$ No treatment for the moderate-risk cohort; $\mathrm{A}_{\mathrm{M}}$ - ACEI and Diu; $\mathrm{B}_{\mathrm{M}}$ - ACEI, Diu and Sta; $\mathrm{NT}_{\mathrm{H}}$ - No treatment for the high-risk cohort; $\mathrm{A}_{\mathrm{H}}$ - ACEI, CCB and Diu; $\mathrm{B}_{\mathrm{H}}-\mathrm{ACEI}, \mathrm{CCB}$, Diu, and Sta.

Fig. 11 Cost effectiveness acceptability frontier for moderate and high CVD risk

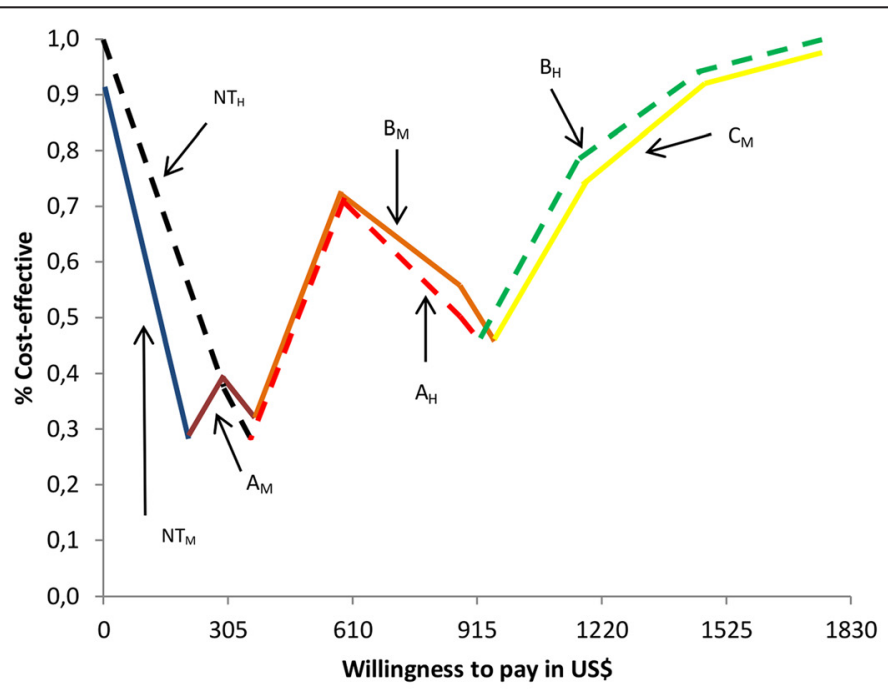

${ }^{1}$ Moderate CVD risk with diabetes - represented by solid lines; ${ }^{2}$ High CVD risk with diabetes represented by dotted lines; $\mathrm{NT}_{\mathrm{M}}$ - No treatment for moderate-risk cohort; $\mathrm{A}_{\mathrm{M}}$ - Sulf, ACEI and CCB; $\mathrm{B}_{\mathrm{M}}$ - Big, Sulf ACEI and CCB; $\mathrm{C}_{\mathrm{M}}$ - Big, Sulf ACEI, CCB and Sta; $\mathrm{NT}_{\mathrm{H}}$ - No treatment for high-risk cohort; $A_{H}$ - Big, Sulf, ACEI and CCB; $B_{H}-$ Big, Sulf, ACEI, CCB and Sta.

Fig. 12 Cost effectiveness acceptability frontier for moderate and high CVD risk with diabetes 


\section{Appendix 6}

Table 8 Expected Value of Perfect Information (EVPI) and population EVPI ${ }^{1}$ according to CVD risk levels

\begin{tabular}{|c|c|c|c|c|c|c|c|c|}
\hline \multirow{2}{*}{$\overline{\text { WTP value (\$) }}$} & \multicolumn{2}{|c|}{ Low risk } & \multicolumn{2}{|c|}{ Moderate risk } & \multicolumn{2}{|c|}{ High risk } & \multicolumn{2}{|c|}{ Very high risk } \\
\hline & EVPI & pop EVPI & EVPI & pop EVPI & EVPI & pop EVPI & EVPI & pop EVPI \\
\hline \multicolumn{9}{|l|}{ CVD risk } \\
\hline 305 & 0.0 & 0.0 & 44 & 382196 & 43 & 379456 & 0.2 & 1413 \\
\hline 610 & 0.0 & 0.0 & 58 & 509069 & 62 & 545863 & 51 & 450067 \\
\hline 915 & 01 & 7683 & 57 & 498410 & 47 & 412599 & 37 & 320778 \\
\hline 1220 & 25 & 223152 & 67 & 590630 & 48 & 424051 & 36 & 319205 \\
\hline 1525 & 38 & 331920 & 80 & 700692 & 52 & 457304 & 39 & 342096 \\
\hline 1830 & 35 & 305884 & 93 & 820013 & 56 & 496261 & 42 & 370022 \\
\hline \multicolumn{9}{|c|}{ CVD risk with diabetes } \\
\hline 305 & 0.2 & 2027 & 55 & 482549 & 93 & 816305 & 38 & 330960 \\
\hline 610 & 38 & 338058 & 14 & 123327 & 16 & 142351 & 18 & 160405 \\
\hline 915 & 68 & 594776 & 21 & 182611 & 26 & 226298 & 08 & 71701 \\
\hline 1220 & 37 & 324309 & 09 & 80525 & 07 & 63077 & 01 & 11007 \\
\hline 1525 & 19 & 166059 & 03 & 22511 & 02 & 13393 & 0.2 & 2188 \\
\hline 1830 & 13 & 115602 & 01 & 6711 & 0.3 & 2937 & 0.1 & 893 \\
\hline
\end{tabular}

${ }_{1}$ Population EVPI for 1000 patients, 10 years, 3 \% discount rate; pop - population; WTP - Willingness to pay 


\section{Appendix 7}

Table 9 Provider perspective results for four CVD risk levels without and with diabetes. All dominated strategies have been excluded

\begin{tabular}{|c|c|c|c|c|c|c|c|c|c|c|c|}
\hline \multicolumn{12}{|l|}{ CVD risk } \\
\hline Strategy & Cost & IC & Eff & $\mathrm{IE}$ & ICER & Strategy & Cost & IC & Eff & $\mathrm{IE}$ & ICER \\
\hline Low risk & & & & & & Moderate risk & & & & & \\
\hline No treatment & 250 & & 0.00 & & & No treatment & 855 & & 0.00 & & \\
\hline Diu & 409 & 159 & 0.22 & 0.22 & 723 & Diu & 903 & 048 & 0.52 & 0.52 & 092 \\
\hline BB Diu & 508 & 099 & 0.32 & 0.10 & 990 & BB Diu & 945 & 042 & 0.77 & 0.25 & 168 \\
\hline ACEI Diu & 617 & 109 & 0.41 & 0.09 & 1211 & ACEI Diu & 1000 & 055 & 1.02 & 0.25 & 220 \\
\hline ACEl Diu Sta & 884 & 267 & 0.49 & 0.08 & 3338 & ACEI Diu Sta & 1188 & 188 & 1.28 & 0.26 & 723 \\
\hline High risk & & & & & & Very high risk & & & & & \\
\hline No treatment & 955 & & 0.00 & & & No treatment & 1161 & & 0.00 & & \\
\hline ACEI BB Diu & 1278 & 323 & 1.40 & 1.40 & 231 & ACEI BB Diu ASA & 1831 & 670 & 2.27 & 2.27 & 295 \\
\hline ACEI CCB Diu & 1347 & 069 & 1.56 & 0.16 & 431 & ACEI CCB Diu ASA & 1905 & 074 & 2.47 & 0.20 & 370 \\
\hline ACEI CCB Diu Sta & 1548 & 201 & 1.83 & 0.27 & 744 & ACEI CCB Diu Sta ASA & 2118 & 213 & 2.76 & 0.29 & 735 \\
\hline \multicolumn{12}{|l|}{ CVD risk with diabetes } \\
\hline Strategy & Cost & IC & Eff & $\mathrm{IE}$ & ICER & Strategy & Cost & IC & Eff & IE & ICER \\
\hline Low risk & & & & & & Moderate risk & & & & & \\
\hline No treatment & 548 & & 0.00 & & & No treatment & 1099 & & 0.00 & & \\
\hline Sulf ACEI CCB & 1027 & 479 & 0.85 & 0.85 & 564 & Sulf ACEI CCB & 1304 & 205 & 1.40 & 1.40 & 146 \\
\hline Big Sulf ACEI CCB & 1371 & 344 & 1.16 & 0.31 & 1110 & Big Sulf ACEI CCB & 1561 & 257 & 2.01 & 0.61 & 421 \\
\hline Big Sulf ACEI CCB Sta & 1633 & 262 & 1.26 & 0.10 & 2620 & Big Sulf ACEI CCB Sta & 1783 & 222 & 2.21 & 0.20 & 1110 \\
\hline High risk & & & & & & Very high risk & & & & & \\
\hline No treatment & 1160 & & 0.00 & & & No treatment & 1516 & & 0.00 & & \\
\hline Sulf ACEI CCB & 1479 & 319 & 1.52 & 1.52 & 210 & Sulf ACEI CCB ASA & 2067 & 551 & 2.54 & 2.54 & 217 \\
\hline Big Sulf ACEI CCB & 1757 & 278 & 2.16 & 0.64 & 434 & Big Sulf ACEI CCB & 2365 & 298 & 3.36 & 0.82 & 363 \\
\hline Big Sulf ACEI CCB Sta & 1978 & 221 & 2.37 & 0.21 & 1052 & Big Sulf ACEI CCB Sta ASA & 2584 & 219 & 3.64 & 0.28 & 782 \\
\hline Big Sulf ACEI ARB CCB Sta & 3022 & 1044 & 2.47 & 0.10 & 10440 & Big Sulf ACEl ARB CCB Sta ASA & 3585 & 1001 & 3.77 & 0.13 & 7700 \\
\hline
\end{tabular}

IC - Incremental cost; Eff - Effectiveness; IE - Incremental effectiveness; ICER - Incremental cost-effectiveness ratio 
Table 10 Differential discounting results for CVD risk without and with diabetes for four risk levels. All dominated strategies have been excluded

\begin{tabular}{|c|c|c|c|c|c|c|c|}
\hline Strategy & $\begin{array}{l}\text { Base case } \\
\text { oDR - } 3 \%\end{array}$ & $\begin{array}{l}\text { Lower DR } \\
\text { oDR - } 1.5 \%\end{array}$ & $\begin{array}{l}\text { No DR } \\
\text { oDR - } 0 \%\end{array}$ & Strategy & $\begin{array}{l}\text { Base case } \\
\text { oDR - } 3 \%\end{array}$ & $\begin{array}{l}\text { Lower DR } \\
\text { oDR - } 1.5 \%\end{array}$ & $\begin{array}{l}\text { No DR } \\
\text { oDR - } 0 \%\end{array}$ \\
\hline \multicolumn{8}{|l|}{ CVD risk } \\
\hline Low risk & ICER & & & Moderate risk & ICER & & \\
\hline No treatment & & & & No treatment & & & \\
\hline ACEl_Diu & 1327 & 907 & 585 & ACEl_Diu & 164 & 118 & 082 \\
\hline ACEI_Diu_Sta & 3175 & 2121 & 1497 & ACEI_Diu_Sta & 554 & 379 & 262 \\
\hline High risk & & & & Very high risk & & & \\
\hline No treatment & & & & No treatment & & & \\
\hline ACEI_CCB_Diu & 349 & 252 & 176 & ACEI_CCB_Diu_ASA & 498 & 364 & 258 \\
\hline ACEI_CCB_Diu_Sta & 607 & 432 & 293 & ACEI_CCB_Diu_Sta_ASA & 652 & 461 & 315 \\
\hline \multicolumn{8}{|l|}{ CVD risk with diabetes } \\
\hline Low risk & & & & Moderate risk & & & \\
\hline No treatment & & & & No treatment & & & \\
\hline Sulf_ACEI_CCB & 608 & 465 & 311 & Sulf_ACEI_CCB & 115 & 083 & 058 \\
\hline Big_Sulf_ACEI_CCB & 958 & 645 & 430 & Big_Sulf_ACEI_CCB & 256 & 179 & 123 \\
\hline Big_Sulf_ACEI_CCB_Sta & 2480 & 1769 & 1126 & Big_Sulf_ACEI_CCB_Sta & 945 & 675 & 450 \\
\hline High risk & & & & Very high risk & & & \\
\hline No treatment & & & & No treatment & & & \\
\hline Big_Sulf_ACEI_CCB & 309 & 222 & 154 & Big_Sulf_ACEl_CCB_ASA & 350 & 258 & 184 \\
\hline Big_Sulf_ACEI_CCB_Sta & 914 & 640 & 436 & Big Sulf ACEI CCB Sta ASA & 704 & 505 & 346 \\
\hline Big Sulf ACEI ARB CCB Sta & 10300 & 7357 & 4905 & Big Sulf ACEl ARB CCB Sta ASA & 7615 & 4950 & 3536 \\
\hline
\end{tabular}

DR - Discount rate; ICER - Incremental cost-effectiveness ratio 


\section{Appendix 8}

Table 11 Index cohort's characteristics according to CVD risk levels*

\begin{tabular}{|c|c|c|c|c|}
\hline Index cohort & Low risk & Moderate risk & High risk & Very high risk \\
\hline \multicolumn{5}{|l|}{ Without diabetes } \\
\hline Total cholesterol & $4 \mathrm{mmol}$ & $>8 \mathrm{mmol}^{1}$ & $>8 \mathrm{mmol}$ & $>8 \mathrm{mmol}$ \\
\hline Systolic blood pressure & $120-139 \mathrm{mmHg}$ & $140-159 \mathrm{mmHg}^{2}$ & $160-179 \mathrm{mmHg}$ & $>180 \mathrm{mmHg}$ \\
\hline Smoking & No & No & No & Yes \\
\hline Sex & Male & Female & Female & Female \\
\hline \multicolumn{5}{|l|}{ With diabetes } \\
\hline Total cholesterol & $4 \mathrm{mmol}$ & $6 \mathrm{mmol}$ & $7 \mathrm{mmol}^{4}$ & $>8 \mathrm{mmol}$ \\
\hline Systolic blood pressure & $120-139 \mathrm{mmHg}$ & $140-159 \mathrm{mmHg}^{3}$ & $160-179 \mathrm{mmHg}$ & $160-179 \mathrm{mmHg}$ \\
\hline Smoking & No & No & No & Yes \\
\hline Sex & Male & Female & Female & Female \\
\hline
\end{tabular}

*These are the index characteristics of the genders not represented in tie main results. Age groups were: 40-49, 50-59, 60-69, 70-79, 80-89 and 90-99 (Table 12);

$17 \mathrm{mmol}$ used for age group $40-49 ;{ }^{2} 160-179 \mathrm{mmHg}$ applied to age group $40-49 ;{ }^{3} 160-179 \mathrm{mmHg}$ used for age groups $40-59 ;{ }^{4} 6 \mathrm{mmol}$ used for age groups $>60$ years

Table 12 Annual risk of acute myocardial infarction and stroke for low CVD risk males and moderate to very high CVD risk females No previous history of acute myocardial infarction (AMI) or stroke

CVD risk

\begin{tabular}{|c|c|c|c|c|c|c|c|c|}
\hline \multirow[b]{2}{*}{ Age } & \multicolumn{4}{|c|}{ Acute myocardial infarction } & \multicolumn{4}{|l|}{ Stroke } \\
\hline & Low & Moderate & High & Very high & Low & Moderate & High & Very high \\
\hline $40-49$ & 0.0040 & 0.0080 & 0.0100 & 0.0180 & 0.0040 & 0.0030 & 0.0030 & 0.0080 \\
\hline $50-59$ & 0.0060 & 0.0140 & 0.0160 & 0.0250 & 0.0040 & 0.0030 & 0.0040 & 0.0090 \\
\hline $60-69$ & 0.0100 & 0.0180 & 0.0210 & 0.0310 & 0.0050 & 0.0050 & 0.0060 & 0.0160 \\
\hline 70-79 & 0.0140 & 0.0190 & 0.0230 & 0.0330 & 0.0080 & 0.0090 & 0.0110 & 0.0270 \\
\hline 80-89 & 0.0190 & 0.0210 & 0.0250 & 0.0360 & 0.0130 & 0.0160 & 0.0190 & 0.0430 \\
\hline 90-99 & 0.0230 & 0.0230 & 0.0270 & 0.0380 & 0.0150 & 0.0270 & 0.0320 & 0.0640 \\
\hline \multicolumn{9}{|c|}{ CVD risk with diabetes } \\
\hline $40-49$ & 0.0060 & 0.0130 & 0.0160 & 0.0270 & 0.0050 & 0.0050 & 0.0050 & 0.0090 \\
\hline $50-59$ & 0.0090 & 0.0190 & 0.0230 & 0.0360 & 0.0050 & 0.0060 & 0.0060 & 0.0110 \\
\hline $60-69$ & 0.0140 & 0.0210 & 0.0250 & 0.0420 & 0.0070 & 0.0090 & 0.0110 & 0.0190 \\
\hline 70-79 & 0.0190 & 0.0230 & 0.0270 & 0.0440 & 0.0110 & 0.0160 & 0.0190 & 0.0320 \\
\hline 80-89 & 0.0240 & 0.0250 & 0.0290 & 0.0510 & 0.0170 & 0.0270 & 0.0320 & 0.0500 \\
\hline 90-99 & 0.0290 & 0.0270 & 0.0310 & 0.0560 & 0.0190 & 0.0430 & 0.0500 & 0.0710 \\
\hline
\end{tabular}

With previous history of AMI or stroke

CVD risk

\begin{tabular}{|c|c|c|c|c|c|c|c|c|}
\hline \multirow[b]{2}{*}{ Age } & \multicolumn{4}{|c|}{ Acute myocardial infarction } & \multicolumn{4}{|l|}{ Stroke } \\
\hline & Low & Moderate & High & Very high & Low & Moderate & High & Very high \\
\hline $40-49$ & 0.0042 & 0.0088 & 0.0115 & 0.0216 & 0.0045 & 0.0035 & 0.0036 & 0.0106 \\
\hline $50-59$ & 0.0063 & 0.0154 & 0.0184 & 0.0300 & 0.0045 & 0.0035 & 0.0048 & 0.0120 \\
\hline $60-69$ & 0.0105 & 0.0198 & 0.0242 & 0.0372 & 0.0057 & 0.0059 & 0.0072 & 0.0213 \\
\hline 70-79 & 0.0147 & 0.0209 & 0.0265 & 0.0396 & 0.0090 & 0.0105 & 0.0132 & 0.0359 \\
\hline $80-89$ & 0.0200 & 0.0231 & 0.0288 & 0.0432 & 0.0147 & 0.0187 & 0.0228 & 0.0572 \\
\hline $90-99$ & 0.0242 & 0.0253 & 0.0311 & 0.0456 & 0.0170 & 0.0316 & 0.0384 & 0.0851 \\
\hline
\end{tabular}


Table 12 Annual risk of acute myocardial infarction and stroke for low CVD risk males and moderate to very high CVD risk females (Continued)

\begin{tabular}{ccccccccc}
\hline \multicolumn{2}{c}{ CVD risk with diabetes } & & & & & & \\
$40-49$ & 0.0063 & 0.0143 & 0.0184 & 0.0324 & 0.0057 & 0.0059 & 0.0060 & 0.0120 \\
$50-59$ & 0.0095 & 0.0209 & 0.0265 & 0.0432 & 0.0057 & 0.0070 & 0.0072 & 0.0146 \\
$60-69$ & 0.0147 & 0.0231 & 0.0288 & 0.0504 & 0.0079 & 0.0105 & 0.0132 & 0.0253 \\
$70-79$ & 0.0200 & 0.0253 & 0.0311 & 0.0528 & 0.0124 & 0.0187 & 0.0228 & 0.0426 \\
$80-89$ & 0.0252 & 0.0275 & 0.0334 & 0.0612 & 0.0192 & 0.0316 & 0.0384 & 0.0665 \\
$90-99$ & 0.0305 & 0.0297 & 0.0357 & 0.0672 & 0.0215 & 0.0503 & 0.0600 & 0.0944 \\
\hline
\end{tabular}

Table 13 Cost-effectiveness results for low CVD risk males and moderate to very high CVD risk females without and with diabetes. All dominated strategies have been excluded

\begin{tabular}{|c|c|c|c|c|c|c|c|c|c|c|c|}
\hline \multicolumn{12}{|l|}{ CVD risk } \\
\hline Strategy & Cost & IC & Eff & IE & ICER & Strategy & Cost & IC & Eff & IE & ICER \\
\hline Low risk & & & & & & Moderate risk & & & & & \\
\hline No treatment & 799 & & 0.00 & & & No treatment & 991 & & 0.00 & & \\
\hline ACEI Diu & 1202 & 403 & 0.61 & 0.61 & 661 & ACEI Diu & 1330 & 339 & 0.82 & 0.82 & 413 \\
\hline ACEl Diu Sta & 1424 & 222 & 0.74 & 0.13 & 1708 & ACEI Diu Sta & 1525 & 195 & 1.02 & 0.20 & 975 \\
\hline High risk & & & & & & Very high risk & & & & & \\
\hline No treatment & 1112 & & 0.00 & & & No treatment & 1591 & & 0.00 & & \\
\hline ACEI CCB Diu & 1941 & 829 & 1.22 & 1.22 & 680 & ACEI CCB Diu ASA & 3059 & 1468 & 2.30 & 2.30 & 638 \\
\hline ACEI CCB Diu Sta & 2152 & 211 & 1.43 & 0.21 & 1005 & ACEI CCB Diu Sta ASA & 3277 & 218 & 2.56 & 0.26 & 838 \\
\hline \multicolumn{12}{|l|}{ CVD risk with diabetes } \\
\hline Strategy & Cost & IC & Eff & $\mathrm{IE}$ & ICER & Strategy & Cost & IC & Eff & $\mathrm{IE}$ & ICER \\
\hline Low risk & & & & & & Moderate risk & & & & & \\
\hline No treatment & 1175 & & 0.00 & & & No treatment & 1467 & & 0.00 & & \\
\hline Sulf ACEI CCB & 1619 & 444 & 0.95 & 0.95 & 467 & Sulf ACEI CCB & 1756 & 289 & 1.36 & 1.36 & 213 \\
\hline Big Sulf ACEI CCB & 1878 & 259 & 1.30 & 0.35 & 740 & Big Sulf ACEI CCB & 1971 & 215 & 1.94 & 0.58 & 371 \\
\hline Big Sulf ACEI CCB Sta & 2110 & 232 & 1.42 & 0.12 & 1933 & Big Sulf ACEI CCB Sta & 2182 & 211 & 2.13 & 0.19 & 1111 \\
\hline High risk & & & & & & Very high risk & & & & & \\
\hline No treatment & 1602 & & 0.00 & & & No treatment & 2060 & & 0.00 & & \\
\hline Big Sulf ACEI CCB & 2446 & 844 & 2.17 & 2.17 & 389 & Big Sulf ACEI CCB ASA & 3539 & 1479 & 3.37 & 3.37 & 439 \\
\hline Big Sulf ACEI CCB Sta & 2654 & 208 & 2.38 & 0.21 & 991 & Big Sulf ACEI CCB Sta ASA & 3757 & 218 & 3.64 & 0.27 & 807 \\
\hline Big Sulf ACEI ARB CCB Sta & 3700 & 1046 & 2.48 & 0.10 & 10460 & Big Sulf ACEI ARB CCB Sta ASA & 4770 & 1013 & 3.77 & 0.13 & 7792 \\
\hline
\end{tabular}

IC - Incremental cost; Eff - Effectiveness; IE - Incremental effectiveness; ICER - Incremental cost-effectiveness ratio 


\section{Abbreviations}

ACEl: angiotensin converting enzyme inhibitor; AFRO E: African region E; ARB: angiotensin receptor blocker; ASA: soluble aspirin; BB: beta blocker; Big: biguanide; CCB: calcium channel blockers; CEAF: cost-effectiveness acceptability frontier; CHOICE: CHOosing interventions that are cost-effective; CVD: cardiovascular disease; DALY: disability- adjusted life years;

Diu: diuretics; Eff: effectiveness; EVPI: expected value of perfect information; GBD: global burden of disease; GDP: gross domestic product; GHDx: Global Health Data Exchange; IC: incremental cost; ICER: incremental cost-effectiveness ratio; IE: incremental effectiveness; ITC: indirect treatment comparison; MI: myocardial infarction; MSD: Medical Stores Department; MTC: mixed treatment comparison; RCT: randomized control trial; RR: relative risk; SSA: sub-Saharan Africa; Sta: statin; Sulf: sulfonylureas; US\$: United States of America dollar; WHO: World Health Organization; WTP: willingness to pay; YLDs: years lived with disability; YLLs: years of life lost.

\section{Competing interests}

The authors declare that they have no competing interests.

\section{Authors' contributions}

FNN, BR and OFN developed the idea and contributed in the research design. FNN collected all the primary cost data and conducted the analysis. FNN, GMR, ATM, BR and OFN contributed, in the interpretation of results and writing of the different versions of the manuscript. All authors approved the final version of the manuscript.

\section{Acknowledgements}

The authors thank the Ministry of Health and Social Welfare, Tanzania, and the Regional and District Medical Officers of Arusha Municipal Council and Monduli District. We also thank the employees of Mount Meru Hospital, Monduli District Hospital, Kaloleni and Kirurumo Health Centres for their cooperation during cost data collection. Thanks to Dr Elizabeth Sourbut who did the language editing.

\section{Funding}

This work was supported by funding from Norwegian State Education Loan Fund (Statens Lånekassen) and the University of Bergen. The funders had no role in the study design, data collection, analysis, and interpretation and in writing the manuscript.

\section{Author details}

'Ministry of Health and Social Welfare, Dar es Salaam, Tanzania. ${ }^{2}$ Muhimbili University of Health and Allied Sciences, Dar es Salaam, Tanzania. ${ }^{3}$ Centre of International Health, University of Bergen, Bergen, Norway. ${ }^{4}$ Department of Global Public Health and Primary Health Care, University of Bergen, Kalfarveien 31, Post box 7804NO-5020 Bergen, Norway.

\section{Received: 28 March 2015 Accepted: 18 April 2016}

\section{Published online: 17 May 2016}

\section{References}

1. Institute of Health Metrics and Evaluation. Global Heath Data Exchange GBD Compare University of Washington, Seattle, WA, USA: 2013 [cited 2014 December].

2. Bloom DE, Cafiero ET, Jané-Llopis E, Abrahams-Gessel S. The Global Economic Burden of Noncommunicable Diseases. Geneva: World Economic Forum; 2011

3. Njelekela MA, Mpembeni R, Muhihi A, Mligiliche NL, Spiegelman D, Hertzmark E, et al. Gender-related differences in the prevalence of cardiovascular disease risk factors and their correlates in urban Tanzania. BMC Cardiovasc Disord. 2009;9(1):30.

4. Njelekela M, Negishi H, Nara Y, Tomohiro M, Kuga S, Noguchi T, et al. Cardiovascular risk factors in Tanzania: a revisit. Acta Trop. 2001;79(3):231-9.

5. Hendriks ME, Wit FWNM, Roos MTL, Brewster LM, Akande TM, de Beer $I H$, et al. Hypertension in sub-Saharan Africa: Cross-sectional surveys in four rural and urban communities. PLoS ONE. 2012;7(3):e32638.

6. Edwards R, Unwin N, Mugusi F, Whiting D, Rashid S, Kissima J, et al. Hypertension prevalence and care in an urban and rural area of Tanzania. J Hypertens. 2000;18(2):145-52.

7. Bovet P, Ross AG, Gervasoni JP, Mkamba M, Mtasiwa DM, Lengeler C, et al. Distribution of blood pressure, body mass index and smoking habits in the urban population of Dar es Salaam, Tanzania, and associations with socioeconomic status. Int J Epidemiol. 2002;31(1):240-7.

8. Aspray TJ, Mugusi F, Rashid S, Whiting D, Edwards R, Alberti KG, et al. Rural and urban differences in diabetes prevalence in Tanzania: the role of obesity, physical inactivity and urban living. Trans R Soc Trop Med Hyg. 2000;94(6):637-44.

9. David S, Till B. The economics of primary prevention of cardiovascular disease-a systematic review of economic evaluations. Cost Eff Resour Alloc. 2007;5(1):1.

10. Gaziano TA, Steyn K, Cohen DJ, Weinstein MC, Opie LH. Cost-Effectiveness analysis of hypertension guidelines in South Africa. Circulation. 2005;112(23): 3569-76.

11. Ker JA. Decision making using cardiovascular risk reduction and incremental cost effectiveness ratio: a case study. Cardiovasc J Afr. 2008:19(2):97-101.

12. Robberstad B, Hemed Y, Norheim OF. Cost-effectiveness of medical interventions to prevent cardiovascular disease in a sub-Saharan African country - the case of Tanzania. Cost Eff Resour Alloc. 2007;5:3.

13. Murray CJL, Lauer JA, Hutubessy RCW, Niessen L, Tomijima N, Rodgers A, et al. Effectiveness and costs of interventions to lower systolic blood pressure and cholesterol: a global and regional analysis on reduction of cardiovascular-disease risk. Lancet. 2003;361(9359):717-25.

14. Gaziano TA, Opie LH, Weinstein MC. Cardiovascular disease prevention with a multidrug regimen in the developing world: a cost-effectiveness analysis. Lancet. 2006;368(9536):679-86.

15. Gaziano TA. Cardiovascular disease in the developing world and its costeffective management. Circulation. 2005;112(23):3547-53.

16. Gaziano TA. Reducing the growing burden of cardiovascular disease in the developing world. Health Aff. 2007;26(1):13-24.

17. Gaziano TA, Steyn K, Cohen DJ, Weinstein MC, Opie LH. Cost-effectiveness analysis of hypertension guidelines in south africa: absolute risk versus blood pressure level. Circulation. 2005;112(23):3569-76.

18. Sanderson JE, Mayosi B, Yusuf S, Reddy S, Hu S, Chen Z, et al. Global burden of cardiovascular disease. Heart. 2007;93(10):1175.

19. Ministry of Health and Social Welfare. Standard Treatment Guidelines (STG) and the National Essential Medicine List (NEMLIT) for mainland Tanzania. Dar es Salaam: Ministry of Health and Social Welfare; 2007.

20. Ministry of Health and Social Welfare. Standard Treatment Guidelines and the Essential Medicine List (NEMLIT) Tanzania mainland. Dar es Salaam: Ministry of Health and Social Welfare; 2012.

21. Jackson R, Lawes CMM, Bennett DA, Milne RJ, Rodgers A. Treatment with drugs to lower blood pressure and blood cholesterol based on an individual's absolute cardiovascular risk. Lancet. 2005;365(9457):434-41.

22. WHO. Prevention of cardiovascular disease: Guidelines for assessment and management of cardiovascular risk. Geneva: WHO; 2007. ISBN 978924 1547178.

23. National Vascular Disease Prevention Alliance. Absolute cardiovascular disease risk assessment 2014 [cited 2014 September]. Available from: https://heartfoundation.org.au/images/uploads/publications/AbsoluteCVD-Risk-Quick-Reference-Guide.pdf.

24. Eberly LE, Cohen JD, Prineas R, Yang L. Impact of incident diabetes and incident nonfatal cardiovascular disease on 18-year mortality. Diabetes Care. 2003;26(3):848.

25. Lakka HM, Laaksonen DE, Lakka TA, Niskanen LK, Kumpusalo E, Tuomilehto $J$, et al. The metabolic syndrome and total and cardiovascular disease mortality in middle-aged men. JAMA. 2002;288(21):2709.

26. Salomon JA, Vos T, Hogan DR, Gagnon M, Naghavi M, Mokdad A, et al. Common values in assessing health outcomes from disease and injury: disability weights measurement study for the Global Burden of Disease Study 2010. Lancet. 2013;380(9859):2129-43.

27. D'Agostino RB, Wolf PA, Belanger AJ, Kannel WB. Stroke risk profile: adjustment for antihypertensive medication. The Framingham Study. Stroke. 1994;25(1):40-3.

28. Anderson KM, WOLSON P, Odell PM, Kannel WB. An updated coronary risk profile: a statement fo rhealth professionals. Circulation. 1991;83(1):356-62.

29. Goff DC, Lloyd-Jones DM, Bennett G, O'Donnell C, Coady S, Robinson J. 2013 ACC/AHA guideline on the assessment of cardiovascular risk. J Am Coll Cardiol. 2014;63(25 PA).

30. D'Agostino RB, Vasan RS, Pencina MJ, Wolf PA, Cobain M, Massaro JM, et al. General cardiovascular risk profile for use in primary care the Framingham Heart Study. Circulation. 2008;117(6):743-53. 
31. WHO. Global Health Observatory Data Repository Life tables by country United Republic of Tanzania. Available from: http://apps.who.int/gho/data/ ?theme= main\&vid=61770. Accessed Sept 2014.

32. Institute of Health Metrics and Evaluation. GBDX, Tanzania deaths, Both sexes, All ages, 2010. 2013 [cited 2014 July].

33. WHO. CHOosing Interventions that are Cost Effective (WHO-CHOICE). 2003. Available from: http://mww.who.int/choice/cost-effectiveness/en/. Accessed Sept 2014.

34. Ngalesoni F, Ruhago G, Norheim OF, Robberstad B. Economic cost of primary prevention of cardiovascular diseases in Tanzania. Health Policy Plan. 2014;30(7):875-84.

35. Dror DM, Putten-Rademaker V, Koren R. Cost of illness: evidence from a study in five resource-poor locations in India. 2008. Available at SSRN 1016701.

36. Ezzati M, Vander Hoorn S, Rodgers A, Lopez AD, Mathers CD, Murray CJ. Estimates of global and regional potentil health gains from reducing muliple major risk factors. Lancet. 2003;362(9380):271-80.

37. The World Bank. World Development Indicators. 2014. Available from: http://data.worldbank.org/indicator/NY.GDP.PCAP.CD. Accessed Dec 2014.

38. WHO. Health Report 2002. Geneva: WHO; 2002

39. Murray CJL, Vos T, Lozano R, Naghavi M, Flaxman AD, Michaud C, et al. Disability-adjusted life years (DALYS) for 291 diseases and injuries in 21 regions, 1990-2010: a systematic analysis for the Global Burden of Disease Study 2010. Lancet. 2012;380(9859):2197-223.

40. Gray A, Clarke P, Wolstenholme J, Wordsworth S. Applied methods of costeffectiveness analysis in health care. Oxford: Oxford University Press; 2011.

41. Drummond MF, Sculpher M, Torrance G, O'Brien B, Stoddart G. Methods for the economic evaluation of health care programmes. New York: Oxford University Press; 2005.

42. Barton GR, Briggs AH, Fenwick EA. Optimal Cost-Effectiveness Decisions: The Role of the Cost-Effectiveness Acceptability Curve (CEAC), the CostEffectiveness Acceptability Frontier (CEAF), and the Expected Value of Perfection Information (EVPI). Value Health. 2008;11(5):886-97.

43. Fenwick E, Claxton K, Sculpher M. Representing uncertainty: the role of cost-effectiveness acceptability curves. Health Econ. 2001;10(8):779-87.

44. Briggs AH, Claxton K, Sculpher MJ. Decision modelling for health economic evaluation. Oxford: Oxford University Press; 2006.

45. Claxton K, Sculpher M, Culyer A, McCabe C, Briggs A, Akehurst R, et al. Discounting and cost-effectiveness in NICE-stepping back to sort out a confusion. Health Econ. 2006;15(1):1-4.

46. Claxton K, Paulden M, Gravelle H, Brouwer W, Culyer AJ. Discounting and decision making in the economic evaluation of health-care technologies. Health Econ. 2011;20(1):2-15.

47. Gravelle H, Brouwer W, Niessen L, Postma M, Rutten F. Discounting in economic evaluations: stepping forward towards optimal decision rules. Health Econ. 2007:16(3):307-17.

48. Brouwer WB, Niessen LW, Postma MJ, Rutten FF. Need for differential discounting of costs and health effects in cost effectiveness analyses. BMJ. 2005;331(7514):446-8

49. Ortegón M, Lim S, Chisholm D, Mendis S. Cost effectiveness of strategies to combat cardiovascular disease, diabetes, and tobacco use in sub-Saharan Africa and South East Asia: mathematical modelling study. BMJ. 2012;344.

50. McCabe C, Claxton K, Culyer AJ. The NICE cost-effectiveness threshold. Pharmacoecon. 2008;26(9):733-44.

51. Revill P, Walker S, Madan J, Ciaranello A, Mwase T, Gibb DM, et al. Using cost-effectiveness thresholds to determine value for money in low-and middle-income country healthcare systems: Are current international norms fit for purpose? 2014.

52. Jones AM. The Elgar companion to health economics. Northampton, MA USA: Edward Elgar Publishing Cheltenham UK; 2012.

53. Shillcutt MSD, Walker DG, Goodman CA, Mills AJ. Cost effectiveness in lowand middle-income countries. Pharmacoecon. 2009;27(11):903-17.

54. Claxton K, Walker S, Palmer S, Sculpher M. Appropriate perspectives for health care decisions. 2010.

55. Polimeni JM, Vichansavakul K, lorgulescu RI, Chandrasekara R. Why perspective matters in health outcomes research analyses. Int Bus Econ Res J. 2013;12(11): 1503-12.

56. Jönsson B. Ten arguments for a societal perspective in the economic evaluation of medical innovations. Eur J Health Econ. 2009;10(4):357-9.

57. Jansen JP, Fleurence R, Devine B, Itzler R, Barrett A, Hawkins N, et al. Interpreting indirect treatment comparisons and network meta-analysis for health-care decision making: report of the ISPOR task force on indirect treatment comparisons good research practices: part 1. Value Health. 2011; 14(4):417-28.

58. Wright JM, Musini VM. First-line drugs for hypertension. Cochrane Database Syst Rev. 2009:3(3):CD001841.

59. Medical Stores Department, Tanzania. Price Catalogue of Essential Medicines, Diagnostics and Hospital Supplies $2011 \backslash 12$.

60. Bangalore S, Kumar S, Wetterslev J, Messerli FH. Angiotensin receptor blockers and risk of myocardial infarction: meta-analyses and trial sequential analyses of 147020 patients from randomised trials. BMJ. 2011;342:d2234.

61. Holman RR, Paul SK, Bethel MA, Matthews DR, Neil HAW. 10-year follow-up of intensive glucose control in type 2 diabetes. New England Journal of Medicine. 2008;359(15):1577-89.

62. Law M, Morris J, Wald N. Use of blood pressure lowering drugs in the prevention of cardiovascular disease: meta-analysis of 147 randomised trials in the context of expectations from prospective epidemiological studies. BMJ. 2009;338:b1665.

63. Baigent C, Blackwell L, Collins R, Emberson J, Godwin J, Peto R, et al. Aspirin in the primary and secondary prevention of vascular disease: collaborative meta-analysis of individual participant data from randomised trials. Lancet. 2009;373(9678):1849-60

64. Brugts J, Yetgin T, Hoeks S, Gotto A, Shepherd J, Westendorp R, et al. The benefits of statins in people without established cardiovascular disease but with cardiovascular risk factors: meta-analysis of randomised controlled trials. BMJ. 2009;338:b2376.

65. Garbusinski JM, van der Sande MA, Bartholome EJ, Dramaix M, Gaye A, Coleman R, et al. Stroke Presentation and Outcome in Developing Countries A Prospective Study in The Gambia. Stroke. 2005;36(7):1388-93.

66. Heikinheimo T, Chimbayo D, Kumwenda JJ, Kampondeni S, Allain TJ. Stroke outcomes in Malawi, a country with high prevalence of HIV: a prospective follow-up study. PloS one. 2012;7(3):e33765.

\section{Submit your next manuscript to BioMed Central and we will help you at every step:}

- We accept pre-submission inquiries

- Our selector tool helps you to find the most relevant journal

- We provide round the clock customer support

- Convenient online submission

- Thorough peer review

- Inclusion in PubMed and all major indexing services

- Maximum visibility for your research

Submit your manuscript at www.biomedcentral.com/submit
CiolMed Central 